\title{
DINÂMICA DA CONCENTRAÇÃO DA ATIVIDADE INDUSTRIAL NO BRASIL ENTRE 1994 E 2004: UMA ANÁLISE A PARTIR DE ECONOMIAS DE AGLOMERAÇÃO E DA NOVA GEOGRAFIA ECONÔMICA.
}

\author{
Magno Vamberto Batista da Silva* \\ Raul da Mota Silveira Neto ${ }^{\dagger}$
}

\begin{abstract}
Resumo
O trabalho caracteriza os níveis e padrões da concentração da indústria brasileira entre 1994 e 2004, e identifica os determinantes econômicos do crescimento do emprego industrial estadual brasileiro no período. As evidências mostram que desconcentração industrial é mais forte para o segmento intensivo em recursos naturais e mais fraca no de intensivo capital. Novos polos de crescimento do emprego parecem surgir no Nordeste, especialmente, para o segmento intensivo trabalho. As evidências obtidas apontam para a importância das externalidades dinâmicas - as quais são mensuradas pela variável diversidade industrial - dos linkages de mercados e dos custos de transportes para o crescimento do emprego. Essas evidências são coerentes com os argumentos da Nova Geografia Econômica e de Jacobs.
\end{abstract}

\begin{abstract}
The work characterizes the concentration levels and patterns of Brazilian transformation Industry, and identifies the economical determinants of the industrial employment growth for the states of Brazil, in 1994 and 2004. The evidences show that industrial desconcentration is stronger for the intensive capital segment and weaker for natural resources segment. New poles of employment growth seem to appear in the Northeast, especially, for the segment intensive labor. The market linkages, or pecuniary externalities, and of the dynamic externalities, measured by the industrial diversity, are important evidence for the employment growth of transformation industry of Brazilian states. While the transport costs, when controlled by fixed effects, they present negative statistical correlation with the employment growth, consistent to NEG.
\end{abstract}

\footnotetext{
*Professor do PPGE e do Departamento de Economia da UFPB - Campus de João Pessoa e Doutor em Economia pelo PIMES-UFPE

${ }^{\dagger}$ Professor do PIMES - UFPE, Doutor em Economia pela USP e Pesquisador do CNPq
} 


\section{Introdução}

Existem evidências de que a distribuição geográfica da atividade industrial dos países em desenvolvimento é fortemente concentrada (Silveira Neto 2005, Domingues 2005). No Brasil, apesar da desconcentração industrial ocorrida nas últimas décadas, dados de 2004 mostram que 77,4\% do emprego formal da indústria de transformação ainda se encontra concentrado nas regiões Sudeste e Sul, sobretudo, no estado de São Paulo, que responde por 36,6\%. Contudo, entre os anos de 1994 e 2004, verifica-se que há um decrescimento da participação estadual no emprego industrial na região Sudeste, especialmente, no Rio de Janeiro e em São Paulo, e um crescimento nas regiões CentroOeste, Nordeste e Norte do país, o que poderia indicar o surgimento de novos polos dinâmicos de crescimento nestas áreas. Estas evidências geram importantes questões para análise. Qual o padrão observado para a concentração geográfica da indústria brasileira no período recente e o que poderia explicar o crescimento do emprego industrial no período?

As teorias para explicar a concentração das atividades no espaço surgem desde Marshall (1920), um dos pioneiros na argumentação em favor das economias externas como fontes de aglomerações industriais. Recentemente, a partir de Krugman (1991), têm surgido várias contribuições teóricas no sentido de fornecer os microfundamentos para tais argumentos. Por exemplo, Venables (1996) e Fujita et al. (2002) analisam externalidades pecuniárias, Fujita e Thisse (2002), e Fingleton (2003) exploram os technological spillovers. Ao lado desses novos esforços teóricos, os recentes estudos também têm se voltado para identificação empírica desses argumentos (Crozet 2004, Glaeser et al. 1992, Hanson 1998, Henderson 2003, Mion 2004). No Brasil, destacamse os estudos recentes de Silveira Neto (2005), Domingues (2005), Galinari (2006), Chagas (2004) e Oliveira (2004).

Apesar de representar esforços pioneiros e meritórios, a maioria desses trabalhos, para o contexto brasileiro, no entanto, não consegue apreender evidências conjuntas destes argumentos para a aglomeração e, por muitas vezes, não distingue que tipo de externalidade está afetando a concentração industrial, destacando apenas o papel dos retornos crescentes de escala. Além disso, é comum encontrar em alguns desses trabalhos o uso de medidas muito gerais e imprecisas para a escala urbana, a exemplo do tamanho da população. O presente trabalho, portanto, tenta cobrir essas lacunas não preenchidas em estudos anteriores.

O primeiro objetivo do trabalho é caracterizar os níveis e padrões da concentração da indústria de transformação do Brasil, nas microrregiões brasileiras, nos anos polares de 1994 e 2004. O segundo objetivo busca identificar os fatores econômicos determinantes do crescimento do emprego industrial para os estados do Brasil, neste período. Esses fatores captam as externalidades pecuniárias e os custos de transporte associados à Nova Geografia Econômica NGE, e as externalidades dinâmicas, relacionadas às teorias MAR (Marshall 1920, Arrow 1962, Romer 1986).

As evidências obtidas neste trabalho mostram que a concentração industrial é mais forte no setor intensivo capital e relativamente mais fraca no de intensivo em recursos naturais. Clusters locais da participação do emprego são identificados no Sul e Sudeste do país, sobretudo, nas microrregiões de São Paulo, e novos polos de crescimento do emprego parecem surgir na região Nordeste. Os resultados, também, apontam para a existência de evidências 
favoráveis ao papel das conexões de mercado, dos custos de transporte, e das externalidades dinâmicas, captadas pela diversidade industrial, sobre o crescimento do emprego, consistente com a NGE, Venables (1996), Jacobs (1969) e Fingleton (2003).

Além desta introdução, o trabalho possui mais quatro seções. A seção 2 apresenta os argumentos e uma revisão da literatura empírica recente sobre concentração espacial das atividades. A seção 3 evidencia os níveis e padrão espacial da concentração industrial, nas microrregiões brasileiras, para os anos de 1994 e 2004. Na seção 4, trata-se da metodologia e da apresentação dos resultados estimados para o crescimento do emprego. Por fim, o último capítulo apresenta as principais conclusões extraídas deste estudo.

\section{Os Argumentos da Teoria Econômica para a Aglomeração das Atividades e as Evidências Disponíveis}

Nesta seção, são apresentados os diversos argumentos econômicos para explicar a concentração geográfica da atividade econômica. Esses diferentes fatores fornecem a base teórica para explicar o crescimento do emprego industrial brasileiro, tarefa a ser desempenhada na quarta seção deste trabalho.

A despeito das dificuldades iniciais envolvidas na fundamentação econômica para a existência de retornos crescentes, estudos sobre a localização e concentração da atividade econômica no espaço datam de antes do século passado, desde Marshall (1920), um dos pioneiros na argumentação em favor das economias externas, conhecidas também como externalidades Marshallianas, como fontes de aglomerações industriais. Além disso, o papel das economias externas também sempre foi central tanto na explicação dos aglomerados urbanos (Hoover 1948), como, de forma mais geral, para os teóricos da geografia econômica. Mais recentemente, contudo, a partir das contribuições iniciais de Krugman (1991), tem surgido uma série de contribuições teóricas no sentido de dar microfundamentos a parte dos argumentos propostos para explicar a aglomeração das atividades econômicas.

Pioneiros, os modelos de centro-periferia (CP) de Krugman (1991) e Fujita et al. (2002) e a versão dos linkages verticais de Venables (1996) analisam as conexões de mercado ou externalidades pecuniárias, que encorajam as firmas e trabalhadores a se instalarem perto de seus compradores e vendedores de seus produtos e serviços. No modelo de Venables, tais linkages são intersetoriais, e nos dois primeiros estudos são intra-setoriais.

Três forças governam a dinâmica de aglomeração do modelo CP. A primeira é o efeito de acesso ao mercado, na qual as firmas monopolísticas tendem a localizar suas produções próximas aos mercados maiores e a exportar para os mercados pequenos. O segundo é o efeito custo de vida, em que se tem bens mais baratos em regiões com maior presença de firmas industriais. Portanto, essas são as forças indutoras da aglomeração. A terceira força é o efeito competição local, que descreve a tendência das firmas, em mercado de competição imperfeita, estarem localizadas em regiões com existência de poucos competidores, favorecendo, assim, a dispersão das atividades.

A potência dessas forças depende crucialmente do nível de custos de transporte. O efeito competição local é mais forte do que as forças de aglomeração quando os custos de transportes forem muito altos, isto é, com dificuldades de comércio. Porém, na medida em que os custos de transporte caem ou a aber- 
tura comercial torna-se maior, a força de dispersão cai mais rapidamente do que as de aglomeração, de modo que, em algum ponto, estas últimas passam a dominar o efeito de competição. Assim, para algum nível intermediário de custos de transporte há a aglomeração. Já para níveis muito baixos de custos de transporte, a localização deixa de ser relevante.

O estudo de Venables (1996) diferencia-se do modelo proposto por Krugman (1991), na medida em que demonstra que a aglomeração das atividades industriais também pode surgir da interação entre as decisões de localização de firmas de indústrias que são integradas por meio de uma estrutura insumoproduto. Neste contexto, até mesmo sem a mobilidade do trabalho, existem forças capazes de conduzir à aglomeração. Os linkages de mercado que atuam no sentido da aglomeração da atividade produtiva derivam dos efeitos da interação dos custos de comércio, retornos crescentes de escala e competição imperfeita. Os linkages de demanda, em que as indústrias de conexão para trás (dowstream industry) formam o mercado para as indústrias de conexão para frente (upstream industry) e juntamente com os linkages de custos (redução com custos de transporte de insumos intermediários) criam as forças favoráveis à concentração. Por outro lado, os fatores de produção não móveis e demanda final do consumidor são as forças que trabalham contra a aglomeração. Novamente, a depender dos níveis dos custos de transporte, diferentes equilíbrios, com aglomeração ou dispersão, podem ser obtidos.

Fujita e Thisse (2002), retornando mais diretamente ao argumento marshalliano, exploram a presença de technological spillovers. Nesses modelos, o transbordamento do conhecimento é interno à indústria e depende de sua própria escala industrial local, que possibilitaria as cidades se especializarem em determinada atividade. Essas externalidades são chamadas de economias de localização no contexto estático e, algumas vezes, de teorias MAR (Marshall 1920, Arrow 1962, Romer 1986) na forma dinâmica ${ }^{1}$. Por outro lado, Fingleton (2003) propõe um modelo microfundamentado, em que usa uma variável de densidade para representar as externalidades entre indústrias diferentes, semelhante à teoria de Jacobs (1969), em que as firmas e os trabalhadores também podem aprender fora de sua indústria por meio da ideia de fertilização cruzada. Neste caso, importa a escala global e a diversidade do ambiente local, com a informação fluindo entre firmas de indústrias diferentes. Por vezes, associam os termos economias de urbanização e externalidades de Jacobs às suas formas estáticas e dinâmicas, respectivamente.

Em Fujita e Thisse (2002), as externalidades produtivas e amenidades no consumo, derivadas do número de trabalhadores qualificados em uma região, atuam no sentido de favorecer a aglomeração, enquanto a produtividade marginal decrescente e os efeitos de congestão, associados ao aumento populacional em uma região, podem conduzir à dispersão das atividades. Já no estudo de Fingleton (2003), a taxa salarial cresce com o aumento da densidade urbana, na forma de maior densidade de emprego, consistente com o argumento de Jacobs (1969) de que maior diversidade industrial pode conduzir à aglomeração das atividades no espaço. A taxa salarial também é função crescente no nível de eficiência de cada área, que é influenciado pelo nível educacional da população da área, por um indicador de conhecimento técnico da força de tra-

${ }^{1}$ As externalidades dinâmicas, resultantes dos knowledge spillovers ou learning by doing, são tratadas também nos recentes estudos da teoria do crescimento econômico, por exemplo, em Romer 1986, 1990 e Lucas (1988). 
balho, e por spillovers de eficiência entre áreas vizinhas. Portanto, em áreas de maior concentração o produto tende a ser maior, e essa maior produtividade também é acompanhada de aumentos de salários.

As evidências empíricas sobre os argumentos expostos acima para a concentração das atividades são recentes, o que, talvez, seja explicado, em parte, pelos também recentes desenvolvimentos de modelos formais, que incorporam as forças econômicas por trás das tendências da aglomeração. Tais trabalhos empíricos, contudo, representam uma contribuição meritória, na medida em que podem testar e validar esses argumentos teóricos.

Uma importante contribuição empírica destes argumentos é o estudo de Glaeser et al. (1992). Este trabalho testa as implicações das novas teorias do crescimento sobre a concentração das atividades, usando dados de cidades e indústrias americanas referentes aos anos de 1956 e 1987. Seus resultados indicam que as externalidades de conhecimento parecem ocorrer mais entre indústrias diversas do que dentro das próprias indústrias, o que corrobora os argumentos de Jacobs (1969) e Fingleton (2003).

As externalidades dinâmicas também foram foco de estudo de Hanson (1998). O autor estima o efeito da reforma comercial sobre o crescimento do emprego industrial do México, para os anos censitários de 1980 a 1993. Ele verifica o papel das economias de aglomeração, das externalidades "pecuniárias", por meio dos backward e forward linkages, e dos custos de transporte sobre a demanda de emprego naquele país. Seus resultados mostram que os custos de transporte e as conexões de demanda e de oferta afetam positivamente o crescimento do emprego pós-abertura comercial, tendo parte das indústrias migrado do centro do país para as áreas de fronteira, especificamente aquelas próximas aos Estados Unidos.

Já Henderson (2003) estima, principalmente, a extensão e a natureza das economias de escala externas locais para indústrias de alta tecnologia e de maquinarias tradicionais das cidades e metrópoles americanas, no período de 1963-1992. As evidências apontam que externalidades de localização/MAR surgem do número de plantas da própria indústria. Ele mostra ainda que as externalidades estáticas afetam tanto plantas mais maduras e associadas quanto plantas mais jovens e não associadas, enquanto as dinâmicas estão mais presentes em indústria de alta tecnologia de planta única do que multiplantas. Observa-seem multi-plantas. Observa-se, também, a ausência das economias externas de urbanização/Jacobs nas indústrias de alta tecnologia e mais ainda nas indústrias individuais de maquinaria tradicional.

O trabalho de Flingleton (2003), além de apresentar o modelo microfundamentado de densidade econômica, mostra evidências empíricas deste modelo para dados da Grã-Bretanha. Os resultados da regressão para a equação de salários mostram que as variações das taxas salariais entre áreas locais da GrãBretanha estão correlacionadas positivamente com a densidade de emprego, sendo assim, consistentes com as ideias de Jacobs (1969).

Recentemente, Mion (2004) e Crozet (2004) obtiveram evidências favoráveis aos modelos da Nova Geografia Econômica derivados da proposta inicial de Krugman (1991). Os resultados obtidos por Mion (2004) indicam que, de forma bastante robusta, os salários de trabalhadores dos setores industriais das regiões italianas estão positivamente correlacionados com o tamanho de mercado de regiões vizinhas. O estudo de Crozet (2004) propicia avaliação empírica dos linkages de custos, usando dados de migração bilateral para cinco países da Europa, durante o período de 1980 a 1990. Os resultados de- 
monstram evidências favoráveis que os migrantes seguem o mercado potencial, mensurado pelo acesso das fontes de oferta. Assim como o Mion (2004), Hanson (2005) trata dos linkages de demanda. Seus resultados para os municípios americanos também apontam que estes linkages são fortes, mostrando que os salários dos trabalhadores municipais e potencial de mercado estão positivamente correlacionados nas décadas de 1970 a 1990.

Para o contexto brasileiro, estudo de Chagas (2004) para os municípios paulistas identifica retornos crescentes de escala para setores econômicos dinâmicos e retornos constantes para setores mais tradicionais, a exemplo da agropecuária, da prestação de serviços e da administração. Por seu turno, Oliveira (2004) destaca o papel da Nova Geografia Econômica - NGE e dos knowledge spillovers, na medida em que encontra correlação positiva entre variáveis de níveis de educação e medida de urbanização com o crescimento das cidades nordestinas, no período de 1991 a 2000. O autor também mostra que a distância entre os mercados atua negativamente sobre o crescimento econômico de cidades. Para um horizonte maior de tempo e com um universo mais amplo de cidades, Chagas e Júnior (2003) encontram uma relação positiva entre especialização e crescimento das cidades brasileiras no período de 1980 a 1991.

Por sua vez, Silveira Neto (2005) encontra evidências positivas de que as economias de escala favoreceram a concentração regional no Brasil nas décadas de 1950 a 2000. Por seu turno, o estudo de Domingues (2005) identifica a importância dos custos de transporte e de uma medida proxy da escala urbana para a aglomeração das atividades industriais no Brasil, em 2000. Mais recentemente, o trabalho de Galinari (2006) encontra uma relação positiva entre taxa salarial dos municípios paulistas e densidade de emprego, consistente com Jacobs (1969) e Fingleton (2003).

Em suma, estes estudos empíricos apontam para a existência de evidências favoráveis aos fatores econômicos que condicionam a localização e a concentração das atividades econômicas no espaço, quais sejam: os custos de transporte dos bens e serviços, as economias externas, geradas do efeito de transbordamento do conhecimento e da informação e da presença de firmas e trabalhadores localizados perto um dos outros, seja na mesma indústria ou pertencentes a indústrias diferentes e, por fim, os ganhos de localização decorrentes de ligações de demanda e oferta entre indústrias e trabalhadores, responsáveis pelas externalidades pecuniárias. A atuação e a intensidade dessas forças determinam, assim, os níveis de aglomeração das atividades econômicas em dado espaço econômico.

Contudo, os trabalhos empíricos disponíveis para o Brasil não conseguem aprender evidências conjuntas dos argumentos para a aglomeração e, muitas vezes, destacam apenas o papel dos retornos de escala sem fazer distinção de qual tipo de determinante econômico ou de externalidade estaria afetando a aglomeração espacial das atividades econômicas. O presente trabalho, portanto, tenta preencher esta lacuna existente nas evidências empíricas sobre a aglomeração. 


\section{Níveis e Padrão da Concentração Industrial no Brasil: Evidências a partir das Microrregiões do País}

Nesta seção, são apresentadas as evidências obtidas para a concentração industrial a partir das informações da participação microrregional no emprego da indústria de transformação e dos três recortes setoriais, considerados nos anos de 1994 e 2004. No Brasil, há evidências de concentração destas atividades dentro das Unidades da Federação (UF's), assim como da existência de clusters industriais intra-estaduais. Além disso, os efeitos de aglomeração podem atuar apenas a curtas distâncias e, portanto, serem mais fortes quando se considerar unidades geográficas mais desagregadas, tais como as microrregiões e os municípios. O uso da unidade geográfica municípios, no entanto, foi descartado em razão das dificuldades de operacionalização com a agregação dos novos municípios criados neste período.

Seguindo Moreira e Najberg (1998) e Silveira Neto (2005), agregam-se as indústrias de dois dígitos da Classificação Nacional das Atividades Econômicas - CNAE em três segmentos:

Capital Intensivo - Fabricação de produtos têxteis; Fabricação de coque, refino de petróleo, elaboração de combustíveis nucleares e produção de álcool; Fabricação de produtos químicos; Metalurgia básica; Fabricação de produtos em metal - exclusive máquinas e equipamentos; Fabricação de máquinas e equipamentos; Fabricação de máquinas para escritório e equipamentos de informática; Fabricação de máquinas, aparelhos e materiais elétricos; Fabricação de material eletrônico e de aparelhos e equipamentos de comunicações; Fabricação de equipamentos de instrumentação médico-hospitalares, instrumentos de precisão e ópticos, equipamentos para automação industrial, cronômetros e relógios; Fabricação e montagem de veículos automotores, reboques e carrocerias; Fabricação de outros equipamentos de automóveis, e Reciclagem.

Trabalho Intensivo - Confecção de artigos do vestuário e acessórios; Preparação de couros e fabricação de artefatos de couro, artigos de viagem e calçados; Fabricação de celulose, papel e produtos de papel; Edição, impressão e reprodução de gravações, e Fabricação de móveis e indústrias diversas.

Recursos Naturais Intensivos - Fabricação de alimentícios e bebidas; Fabricação de produtos do fumo; Fabricação de produtos de madeira; Fabricação de artigos de borracha e plástico, e Fabricação de minerais nãometálicos.

Os autores do primeiro dos estudos citados construíram esta classificação a partir das informações da matriz de insumo-produto nacional do ano de 1995 e das contas nacionais de 1996 do país. Esta classificação da indústria de transformação é relativa à intensidade de fator de produção e reflete as necessidades diretas e indiretas de cada setor, e parece ser relevante, ao estudar crescimento do emprego ou concentração industrial, já que este agrupamento industrial reflete os diferentes níveis de mobilidades geográficas dos fatores de produção ${ }^{2}$. Esta seção segue com as seguintes subseções. A primeira descreve as tendências e a evolução da concentração industrial nas microrregiões,

\footnotetext{
${ }^{2}$ Neste cálculo, de acordo com Moreira e Najberg (1998), é comparada a intensidade relativa
} 
em termos da participação do emprego em 1994-2004, segundo a indústria de transformação e seus segmentos. Em seguida, identificam os clusters ou outliers da participação microrregional do emprego industrial. Na última, identificam-se as áreas caracterizadas como polos dinâmicos de crescimento do emprego.

\subsection{Concentração Industrial: Evidências para Microrregiões do Brasil}

Evidências iniciais sobre a concentração industrial são extraídas a partir da Tabela 1, a seguir, onde são registradas as dez microrregiões ${ }^{3}$ com maiores participações no emprego da indústria de transformação (IT) e dos três segmentos industriais do Brasil, nos anos de 1994 e 2004. A característica marcante é a forte concentração espacial da indústria de transformação, principalmente, nas microrregiões localizadas nos estados da região Sul e Sudeste. A microrregião de São Paulo responde pela maior participação, 19,46\% do emprego da IT, em 1994, e 11,44\%, em 2004, o que indica uma queda de $41,21 \%{ }^{4}$. Destaca-se a presença de Fortaleza, única microrregião não pertencente ao eixo Sul-Sudeste do país, que responde por 1,69\% e 1,76\%, nestes dois anos, e sobe da $9^{a}$ para a $8^{a}$ posição na lista das dez.

Este caráter concentrador também é observado para os recortes setoriais, em que, novamente, São Paulo apresenta-se como a microrregião de maior participação. Porém, há clara queda desta participação, no período analisado. Novamente, chama-se atenção para a microrregião de Fortaleza, presente em dois dos três segmentos, com maior destaque no de trabalho intensivo, onde sobe da $7^{\text {a }}$ para a $4^{\text {a }}$ colocação na lista. No setor capital intensivo, ressalta-se, entre as dez, a presença, em 2004, da microrregião de Manaus-AM. Por fim, o segmento recursos naturais intensivos tem relativamente melhor distribuição geográfica do emprego.

A contribuição dessas dez maiores participações microrregionais no emprego industrial, em 1994 e 2004, respectivamente, é: 45,38\% e 33,95\% para a indústria de transformação, $56,31 \%$ e $46,55 \%$ para o segmento capital intensivo, $49,95 \%$ e $36,58 \%$ para o de trabalho intensivo e $33,42 \%$ e $22,79 \%$ para o de recursos naturais intensivos. Isso implica que, em todos eles, a participação do emprego do total das dez microrregiões teve decrescimento de, respectivamente, $25,19 \%, 17,33 \%, 26,77 \%$ e $31,81 \%$. Ressalta-se, ainda, que,

de cada setor com aquela obtida para a indústria de transformação. Sendo assim, para que um setor seja considerado intensivo em um dos fatores seria necessário obter o coeficiente de intensidade maior do 1 (um) em relação aos outros dois fatores, comparativamente a média da indústria. Por exemplo, um segmento industrial é considerado intensivo em trabalho se:

$$
r w_{j}=\left[\frac{f_{r j} / f_{w j}}{f_{r M} / f_{w M}}\right]<1 \quad \text { e } \quad k w_{j}=\left[\frac{f_{k j} / f_{w j}}{f_{k M} / f_{w M}}\right]<1
$$

onde $f_{k j}, f_{w j}$ e $f_{r j}$ se definem, na ordem, pelas necessidades totais do fator capital, trabalho e recursos naturais por unidade do produto $j, f_{k M}, f_{w M}$ e $f_{r M}$ representam os requerimentos médios por cada um desses fatores por unidade do produto da indústria manufatureira e $r w_{j} \mathrm{e}$ $k w_{j}$ são os coeficientes de intensidades.

3 Para poupar espaço, optou-se por apresentar os resultados das dez maiores microrregiões das 558 existentes. A participação destas dez parece ser um número razoável para os propósitos do trabalho, já que as demais têm, relativamente, participações do emprego pequenas.

4 Tomando as grandes regiões, o Sudeste é a única a apresentar queda na participação do emprego da indústria de transformação e dos segmentos industriais no período entre 1994 e 2004 , registrando diminuição de $15,67 \%$ para a IT, de 11,43\% para o segmento capital intensivo, $17,41 \%$ para trabalho intensivo e $16,72 \%$ para recursos naturais intensivo. 
Tabela 1: As dez microrregiões com maiores participações no emprego total do país - por indústria de transformação e segmentos industriais - \%: 1994 e 2004

\begin{tabular}{|c|c|c|c|c|c|}
\hline \multicolumn{6}{|c|}{ Indústria de Transformação - IT } \\
\hline Sigla_UF & Nome_micro & 1994 & Sigla_UF & Nome_micro & 2004 \\
\hline SP & São Paulo & 19,46 & SP & São Paulo & 11,44 \\
\hline RJ & Rio de Janeiro & 5,75 & RS & Porto Alegre & 3,67 \\
\hline RS & Porto Alegre & 4,27 & RJ & Rio de Janeiro & 3,44 \\
\hline $\mathrm{SP}$ & Campinas & 3,31 & $\mathrm{SP}$ & Campinas & 3,09 \\
\hline MG & Belo Horizonte & 3,16 & MG & Belo Horizonte & 2,70 \\
\hline PR & Curitiba & 2,29 & PR & Curitiba & 2,55 \\
\hline $\mathrm{SP}$ & Guarulhos & 2,08 & RS & Caxias do Sul & 1,89 \\
\hline RS & Caxias do Sul & 1,72 & $\mathrm{CE}$ & Fortaleza & 1,76 \\
\hline $\mathrm{CE}$ & Fortaleza & 1,69 & SC & Blumenau & 1,76 \\
\hline SC & Blumenau & 1,66 & $\mathrm{SC}$ & Joinvile & 1,65 \\
\hline \multicolumn{6}{|c|}{ Segmento Capital Intensivo $-\mathrm{K}$} \\
\hline Sigla_UF & Nome_micro & 1994 & Sigla_UF & Nome_micro & 2004 \\
\hline SP & São Paulo & $\overline{25,52}$ & SP & São Paulo & 16,34 \\
\hline RJ & Rio de Janeiro & 5,65 & SP & Campinas & 5,29 \\
\hline $\mathrm{SP}$ & Campinas & 4,99 & RJ & Rio de Janeiro & 3,77 \\
\hline MG & Belo Horizonte & 3,89 & MG & Belo Horizonte & 3,71 \\
\hline RS & Porto Alegre & 3,58 & RS & Porto Alegre & 3,50 \\
\hline $\mathrm{SP}$ & Guarulhos & 3,17 & PR & Curitiba & 3,33 \\
\hline $\mathrm{SP}$ & São Jose dos & 2,75 & SP & São Jose dos & 2,86 \\
\hline & Campos & & & Campos & \\
\hline PR & Curitiba & 2,38 & $\mathrm{SP}$ & Guarulhos & 2,65 \\
\hline SC & Joinvile & 2,20 & SC & Joinvile & 2,56 \\
\hline SP & Sorocaba & 2,20 & AM & Manaus & 2,53 \\
\hline \multicolumn{6}{|c|}{ Segmento Trabalho Intensivo - L } \\
\hline Sigla_UF & Nome_micro & 1994 & Sigla_UF & Nome_micro & 2004 \\
\hline SP & $\overline{\text { São Paulo }}$ & $\overline{18,18}$ & SP & $\overline{\text { São Paulo }}$ & $\overline{10,65}$ \\
\hline RS & Porto Alegre & 8,00 & RS & Porto Alegre & 6,15 \\
\hline $\mathrm{RJ}$ & Rio de Janeiro & 6,91 & $\mathrm{RJ}$ & Rio de Janeiro & 3,83 \\
\hline RS & $\begin{array}{l}\text { Gramado- } \\
\text { Canela }\end{array}$ & 3,03 & $\mathrm{CE}$ & Fortaleza & 2,99 \\
\hline MG & Belo Horizonte & 2,73 & RS & $\begin{array}{l}\text { Gramado- } \\
\text { Canela }\end{array}$ & 2,97 \\
\hline RS & Caxias do Sul & 2,55 & SC & Blumenau & 2,35 \\
\hline $\mathrm{CE}$ & Fortaleza & 2,39 & RS & Caxias do Sul & 2,08 \\
\hline SC & Blumenau & 2,31 & $\mathrm{SP}$ & Franca & 1,98 \\
\hline SP & Franca & 2,09 & MG & Belo Horizonte & 1,98 \\
\hline PR & Curitiba & 1,76 & PR & Curitiba & 1,59 \\
\hline
\end{tabular}


Tabela 1: continuação

\begin{tabular}{|c|c|c|c|c|c|}
\hline \multicolumn{6}{|c|}{ Segmento Recursos Naturais Intensivo - RN } \\
\hline Sigla_UF & Nome_micro & 1994 & Sigla_UF & Nome_micro & 2004 \\
\hline SP & São Paulo & 12,21 & SP & São Paulo & 6,54 \\
\hline RJ & Rio de Janeiro & 5,03 & RJ & Rio de Janeiro & 2,77 \\
\hline PR & Curitiba & 2,56 & PR & Curitiba & 2,39 \\
\hline MG & Belo Horizonte & 2,48 & MG & Belo Horizonte & 2,11 \\
\hline RS & Porto Alegre & 2,44 & RS & Porto Alegre & 2,00 \\
\hline SP & Campinas & 2,34 & SP & Campinas & 1,85 \\
\hline $\mathrm{PE}$ & $\begin{array}{l}\text { Mata } \\
\text { Meridional } \\
\text { Pernambucana }\end{array}$ & 1,86 & CE & Fortaleza & 1,42 \\
\hline $\mathrm{CE}$ & Fortaleza & 1,66 & $\mathrm{AL}$ & $\begin{array}{l}\text { São Miguel dos } \\
\text { Campos }\end{array}$ & 1,35 \\
\hline PE & Recife & 1,47 & GO & Goiânia & 1,18 \\
\hline PE & $\begin{array}{l}\text { Mata } \\
\text { Setentrional } \\
\text { Pernambucana }\end{array}$ & 1,38 & SP & Sorocaba & 1,18 \\
\hline
\end{tabular}

Fonte: Elaboração dos autores a partir dos dados da RAIS.

das microrregiões que estavam nesta lista em 1994, seis perdem participação na IT em 2004. Em relação aos setores, cinco microrregiões perdem em capital intensivo, oito perdem em trabalho intensivo e todas as dez perdem no segmento de recursos naturais intensivos.

Estes resultados conduzem, assim, a outras duas importantes observações, que podem ser confirmadas pelos resultados do índice de Gini, ${ }^{5}$ na Tabela 2, a seguir. A primeira é em relação à hierarquia da concentração. O índice é, assim, obtido para os conjuntos industriais na seguinte ordem decrescente, válido para os dois anos polares: o setor capital intensivo, trabalho intensivo, indústria de transformação como um todo e setor intensivo em recursos naturais. Nota-se, então, que o setor capital intensivo é o mais concentrado e o recursos naturais intensivo é o menos concentrado.

A segunda observação a ressaltar é a queda ocorrida no índice de Gini, no período analisado, o que reflete a tendência à desconcentração da indústria brasileira ${ }^{6}$. Este índice para a IT teve queda relativa de $8,00 \%$. Enquanto o setor capital intensivo obteve o menor recuo relativo $(4,29 \%)$, seguido por trabalho intensivo $(6,75 \%)$ e pelo o de recursos naturais intensivo $(8,66 \%)$. Portanto, os dados do Gini indicam que a desconcentração é mais forte neste último setor e é menos intensa no segmento de capital. A hierarquia da con-

\footnotetext{
${ }^{5} \mathrm{O}$ índice de Gini é uma medida global, e largamente utilizada em estudos regionais para mensurar a concentração industrial. Neste trabalho, este índice é mensurado a partir da ordenação crescente das participações microrregionais no emprego total. Coloca-se, então, a soma acumulada destas participações no eixo vertical e a soma acumulada dos pesos microrregionais no número total das microrregiões no eixo horizontal. Para consultar sobre a metodologia do cálculo do GINI, consulte, dentre outros estudos, Hoffmann (1998).

${ }^{6}$ Evidências sobre concentração e evolução industrial no Brasil podem ser encontradas, também, nos estudos de Cano (1998), Pacheco (1999), Bonelli (1996), de Azevedo e Toneto Júnior (2001) e, mais recentemente, Silveira Neto (2005).
} 
Tabela 2: Índice de Gini para microrregiões e indústrias

\begin{tabular}{lcc}
\hline \multirow{2}{*}{ Tipo da indústria } & \multicolumn{2}{c}{ Indice de Gini } \\
\cline { 2 - 3 } & 1994 & 2004 \\
\hline Indústria de transformação & 0,8464 & 0,7787 \\
Segmentos intensivos em capital & 0,9120 & 0,8729 \\
Segmentos intensivos em trabalho & 0,8904 & 0,8303 \\
Segmentos intensivos em recursos naturais & 0,7859 & 0,7178 \\
\hline
\end{tabular}

Fonte: Cálculos dos autores a partir dos dados da RAIS.

centração industrial pode ser vista também a partir das curvas de concentração.

Uma ilustração dos diferentes níveis de concentração industrial destes segmentos, entre 1994 e 2004, também é apresentada a partir das Figuras 1(a) e 1(b). Cada uma das curvas apresenta a participação acumulada das microrregiões, calculada a partir da ordenação decrescente das mesmas, no emprego industrial para a indústria de transformação e os diferentes segmentos. Cabe lembrar que, quanto mais distante uma curva estiver posicionada da origem dos eixos cartesianos, maior o grau de concentração industrial. Sendo assim, constata-se que, neste período, o setor mais concentrado é o de intensivo em capital e o menos concentrado é o de intensivo em recursos naturais.

Embora os níveis de concentração pareçam ser semelhantes, a análise minuciosa destas curvas revela redução da concentração no período investigado. Com efeito, no ano de 1994, observa-se a partir da Figura 1(a) que, por exemplo, as 50 microrregiões com maiores participações no emprego total da IT foram responsáveis por cerca de $74 \%$ do emprego gerado na indústria de transformação. Já as 50 microrregiões que mais participam no emprego do setor intensivo em capital respondem em torno de $85 \%$ do emprego total deste segmento industrial, enquanto nos setores intensivo em trabalho e intensivo em recursos naturais esse valor se aproxima de $80 \%$ e $63 \%$ do emprego total gerado nos respectivos segmentos.

No ano de 2004, observa-se a partir da Figura 1(b) que, as cinqüentas maiores microrregiões contribuem com cerca de 63\% do emprego total da IT, $78 \%$ do emprego gerado no segmento intensivo em capital, $69 \%$ do emprego gerado no de intensivo em trabalho e 53\% do emprego gerado no de intensivo em recursos naturais. Isto revela a segunda importante observação, isto é, o processo de desconcentração industrial do Brasil em curso.

Em resumo, essas evidências confirmam, para o período analisado, que o setor mais concentrado é o de capital intensivo e o menos concentrado é o de recursos naturais intensivos. Essa hierarquia, também, é válida para a desconcentração industrial, onde a queda do índice de Gini no período analisado é menor para o segmento de capital intensivo e maior para o segmento de recursos naturais intensivo, considerando para o cálculo deste indicador a variável da participação do emprego industrial das microrregiões. 


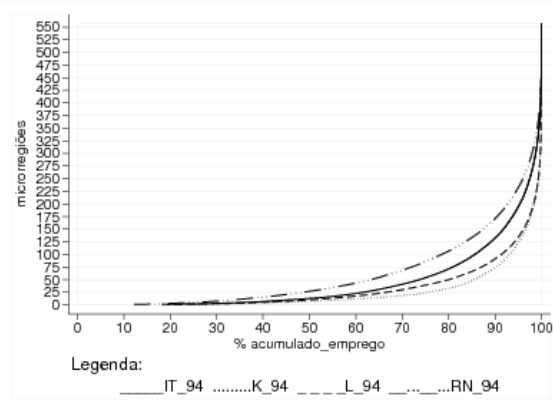

(a) 1994

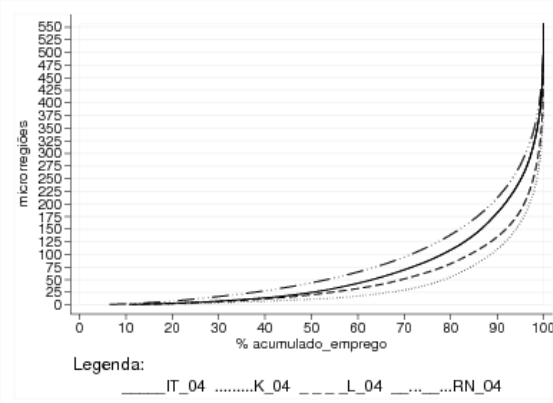

(b) 2004

Fonte: Elaboração dos autores a partir dos dados da RAIS.

Figura 1: Curvas de concentração do emprego microrregional estadual em 1994 e 2004

\subsection{Identificação de Clusters e Outliers Espaciais}

Nesta subseção, faz-se o uso de estatística espacial, tal como o I de Moran, ${ }^{7}$, que tem como finalidade testar se existe associação espacial nos dados, no caso deste estudo, os de emprego industrial. Segundo Anselin (1995), a estatística I de Moran global busca medir a autocorrelação espacial global dos dados. Neste caso, o indicador mostra um único valor para medir a associação espacial de todo o conjunto de observações. Enquanto a medida do indicador local de associação espacial (LISA) permite, para cada observação, verificar a existência de clusters ou aglomerações espaciais significativos, de valores similares, em torno daquela observação. Para a construção desses indicadores, será considerada uma matriz de pesos espaciais de contigüidade do tipo queen, a fim de capturar os efeitos de vizinhança ou de contigüidade sobre os dados. Este tipo de matriz inclui todos os pontos comuns na sua definição, ou seja, para definir os vizinhos, são levados em conta as fronteiras e os vértices. Também foi utilizada uma matriz mais simples do tipo rook, ${ }^{8}$, que considera apenas as fronteiras comuns entre as áreas. Os resultados estimados com essa matriz, contudo, não sofreram alterações.

No presente estudo, o indicador utilizado foi, então, a estatística I de Moran local (LISA). A medida global da autocorrelação espacial pode não ser capaz de identificar padrões locais de associação espacial, tais como clusters e outliers locais, fato que faz recorrer ao uso da estatística local ${ }^{9}$ da associação espacial. De acordo com Ansellin (1995), a medida de associação espacial global $(I)$ e a medida de associação espacial local - LISA $\left(I_{l}\right)$ são calculadas,

\footnotetext{
${ }^{7} \mathrm{Na}$ análise espacial de dados, existem duas medidas para este indicador, mensuradas pelo I de Moran global e pelo o I de Moral local (LISA).

${ }^{8} \mathrm{Na}$ literatura da econometria espacial, outras matrizes são possíveis, como aquelas de distâncias entre as unidades geográficas.

${ }^{9}$ Cálculos feitos para a medida global da estatística espacial, mas não apresentados aqui neste trabalho, indicam que I de Moran global foi estatisticamente significante a 1\% para todos os conjuntos econômicos. Tanto no teste global quanto no local foram realizados para 999 permutações aleatórias, considerando-se uma matriz de pesos espaciais de contigüidade do tipo queen.
} 
respectivamente, por:

$$
I=\frac{\sum_{i=1}^{n} \sum_{j=1}^{n} w_{i j} y_{i} y_{j}}{\sum_{i=1}^{n} y_{i}^{2}} \text { e } \quad I_{l}=\frac{y_{j} \sum_{j=1}^{n} w_{i j} y_{i}}{\sum_{i=1}^{n} y_{i}^{2}},
$$

onde $n$ indica o número de observações, $w_{i j}$ é os elementos da matriz de pesos espaciais ${ }^{10}, y_{i}$ e $y_{j}$ são os valores da variável em questão, medida em desvio em torno da média, e os índices $i$ e $j$ referem as diferentes localidades. A variável em questão trata-se da variável de interesse da localidade, ou seja, refere-se às observações individuais de cada unidade espacial. No presente estudo, esta é mensurada tanto pela participação microrregional no emprego da indústria de transformação e dos segmentos industriais nos anos de 1994 e 2004, quanto pelo crescimento desta participação para estes mesmos conjuntos econômicos neste período.

A medida local da estatística espacial (LISA) é codificada por tipo de autocorrelação espacial existente. Há, assim, quatro possíveis tipos de associação espacial para este caso, sendo dois com correlação espacial positiva, denominados de clusters espaciais $^{11}$ (alto - alto e baixo - baixo). Por um lado, esta medida mostra uma forma de associação espacial positiva, do tipo "alto - alto", quando uma localidade que possui o valor da variável de interesse acima da média tem vizinhos cujos valores também estão acima da média. Enquanto a do tipo "baixo - baixo" é identificada quando o valor da variável que está abaixo da média para uma localização é cercado por vizinhos cujos valores também estão abaixo da média.

Por outro lado, identifica-se a associação espacial negativa, do tipo "alto baixo", quando o valor da variável acima da média para uma unidade geográfica é cercado por vizinhos cujos valores estão abaixo da média. O contrário é válido para a associação espacial do tipo "baixo - alto". Estes dois casos são designados na literatura sobre regimes espaciais como outliers espaciais. Em outras palavras, desde que a medida LISA seja estatisticamente significante, os clusters espaciais são identificados quando o valor da variável de interesse de uma localização é muito similar aos valores da sua vizinhança, sendo os efeitos do cluster extensíveis aos demais vizinhos. Ao contrário, os outliers são classificados quando tais valores são dissimilares e onde os efeitos espaciais se restringem a própria localidade.

Sendo assim, nas aglomerações ou clusters $^{12}$ espaciais do tipo AA, são identificadas as microrregiões que possuem alta participação de emprego cujas áreas vizinhas também possuem altas participações de emprego. O tipo BB identifica microrregiões com baixa participação de emprego cujas áreas vizinhas também possuem baixa participação de emprego. Em ambos os casos, existem efeitos de vizinhança. Enquanto o outlier do tipo AB registra as

\footnotetext{
10 Aqui, no cômputo desta matriz, a vizinhança para cada observação é formalizada por meio de uma matriz de contigüidade do tipo queen como ressaltado no penúltimo parágrafo da página anterior.

11 Ao longo do texto, estas duas formas de associação espacial serão descritas como os tipos $\mathrm{AA}$ e $\mathrm{BB}$, respectivamente. Já as duas formas de autocorrelação espacial local negativa serão abreviadas para $\mathrm{BA}$ e $\mathrm{AB}$.

12 Assim como a denominação de outliers, o termo cluster (aglomeração) está sendo usado neste trabalho como um tipo de identificação de regimes espaciais, que no caso da forma AA expressa correlação espacial de duas ou mais microrregiões com elevada participação no emprego industrial. Então, esta forma de identificar as aglomerações espaciais pode ser diferente daquelas obtidas em estudos que usam medidas tradicionais para caracterizar as aglomerações industriais.
} 
microrregiões de alta participação do emprego com localidades vizinhas que possuem baixa participação de emprego. No tipo BA, identificam-se as microrregiões de baixa participação de emprego cujas localidades vizinhas têm alta participação de emprego.

A Tabela 3, adiante, mostra o número por tipo de associações espaciais locais estatisticamente significantes em cada unidade da federação, identificados a partir da participação microrregional do emprego nos quatros conjuntos econômicos (indústria de transformação e os segmentos intensivos em capital, em trabalho e em recursos naturais). Em geral, o tipo AA da correlação espacial local é registrado, particularmente, nas regiões Sudeste e Sul, com maior incidência no estado de São Paulo, estado que tem apresentado um declínio do número de clusters AA em favor de estados da região sul (Santa Catarina e Rio Grande do Sul). Isto é consistente com o fato da desconcentração industrial acontecer de forma concentrada, direcionada, principalmente, para os estados do Sul do país, o que confirma resultados de trabalhos anteriores, a exemplo de Pacheco (1999). O cluster do tipo BB é mais evidente nas regiões Nordeste e Norte. O outliers tipo BA é notado mais nas regiões Sudeste e Sul, porém, chama a atenção, no setor trabalho intensivo, o registro de cinco deles no estado do Ceará, em 2004. Já o do tipo AB fez-se presente em menor número, aparecendo em Manaus, em alguns estados do Nordeste e no Mato Grosso. Os números de associação espacial, no período, variam menos no setor capital intensivo e variam mais no setor de recursos naturais intensivo, fato que é consistente com a menor desconcentração ocorrida no primeiro setor e a maior no segundo segmento.

Das formas de associação espacial registradas neste trabalho, a mais relevante de todas é a do tipo AA, já que demonstra a correlação espacial significativa entre duas ou mais microrregiões com alta participação de emprego, de modo que isto reflete a forte dependência ou integração econômica entre esses espaços. Segue, assim, a Tabela 4, a qual mostra as microrregiões identificadas como este tipo de associação espacial ou aglomeração industrial, considerado para os quatros conjuntos econômicos, citados no parágrafo anterior. Também é registrado o crescimento das participações do emprego para cada uma das unidades geográficas na qual se identifica esse regime espacial, tanto em 1994 quanto em 2004.

Na Tabela 4, são identificados, então, 23 clusters da indústria de transformação no ano de 1994, todos localizados nas regiões Sudeste e Sul, com destaque para o estado de São Paulo, que registra 18. No ano de 2004, o número total cai para 21, dos quais São Paulo aparece com 14. Constata-se, também, que todos os clusters do Sul do país tiveram crescimento da participação do emprego, sendo o maior deles registrado Itajaí-SC. Neste período, observa-se, ainda, um aumento daqueles identificados para região Sul, fato que é consistente com a desconcentração industrial, mas direcionada, principalmente, mas não exclusivamente, para estados próximos de São Paulo.

Em relação ao segmento de capital intensivo, identificam-se 23 clusters industriais, tanto em 1994 quanto em 2004. Destes, Itajaí-SC é a microrregião que apresenta o maior crescimento da participação do emprego e Serrana-RJ o maior decrescimento. No período considerado, há redução de apenas um deles no estado de São Paulo, enquanto Santa Catarina ganha um. Isto parece ser consistente com o fato da desconcentração industrial, neste setor, estar acontecendo de forma concentrada.

Para o segmento trabalho intensivo, são registrados 24 clusters. Destacam- 
se o surgimento de um cluster na microrregião de Pacajús-CE, a maior incidência de clusters em Santa Catarina e menor no Rio Grande do Sul. Isso sugere, então, um enfraquecimento desta atividade industrial nos estados de São Paulo e Rio Grande do Sul, e fortalecimento nos estados de Santa Catarina e Ceará. De fato, observa-se a microrregião de São Paulo com o maior decrescimento da participação do emprego e boa parte das microrregiões gaúchas também. Nota-se ainda que o maior crescimento é obtido pela microrregião de Pacajus-CE.

Por fim, entre 1994 e 2004, o número de clusters para o caso do setor recursos naturais intensivos aumenta de 25 para 29. Dentre todas essas áreas, as microrregiões de Guaporé-RS e Itajaí-SC exibem os maiores desempenhos de crescimento da participação do emprego e, de novo, São Paulo-SP demonstra a maior queda. Comparativamente aos casos anteriores, observa-se, então, que os clusters aparecem em mais estados, inclusive no Nordeste. Esses números estão em sintonia com o fato de este segmento sofrer a maior desconcentração industrial e ser o menos concentrado de todos os conjuntos econômicos considerados.

\subsection{Identificação dos Polos Dinâmicos de Crescimento}

A Tabela 5, a seguir, apresenta os resultados do I de Moran local aplicado ao crescimento da participação microrregional ${ }^{13}$, a fim de descobrir as áreas mais dinâmicas em termos deste crescimento. Os clusters do tipo AA são observados, principalmente, no Nordeste, com destaque para o número registrado no Ceará, e no estado do Mato Grosso. O tipo BB é percebido, sobretudo, nas regiões Sudeste e Sul, mas também apresenta alguma incidência nos estados das regiões Nordeste e Norte. Já os outliers BA são observados, particularmente, em áreas pertencentes ao Nordeste, enquanto o tipo AB é registrado com fraca incidência em alguns estados nordestinos, no Paraná e no Mato Grosso do Sul.

Na Tabela 6, adiante, destacam-se as microrregiões identificadas como clusters do tipo AA, e registram-se, também, as participações do emprego e o crescimento destas para cada uma das áreas identificadas como clusters significativos em 1994 e 2004. Em todos os conjuntos econômicos, as microrregiões identificadas como clusters apresentam pequena participação do emprego, porém, com elevado crescimento. São registradas, então, nove áreas com associação espacial positiva significante, do tipo AA, para a indústria de transformação, distribuídas três no Ceará, uma na Paraíba, outra em Sergipe e quatro no Mato Grosso.

Em relação aos recortes setoriais, notam-se: oito clusters no segmento de capital intensivo, dos quais dois estão no Rio Grande do Norte, três em Minas Geraisem Minas Gerais, dois no Mato Grosso do Sul e um no Mato Grosso; 12 no segmento de trabalho intensivo, localizados cinco no Ceará, um na Paraíba, um em Sergipe, três na Bahia e dois em Minas Geraisem Minas Gerais e, finalmente, oito são encontrados no segmento de recursos naturais intensivo, sendo dois situados no Rio Grande do Norte, três na Paraíba e três no Mato Grosso. Portanto, as evidências sugerem que as áreas de maior dinamismo

\footnotetext{
${ }^{13}$ A diferença que surge aqui em relação ao indicador utilizado na seção anterior, se deve apenas a mudança da variável de interesse, os $y_{i}$ e $y_{j}$ (crescimento da participação microrregional do emprego, ao invés da participação). Então, a identificação da associação espacial do tipo AA revela a existência de cluster local com alto crescimento da participação do emprego cujos vizinhos apresentam alto crescimento, e assim por diante.
} 


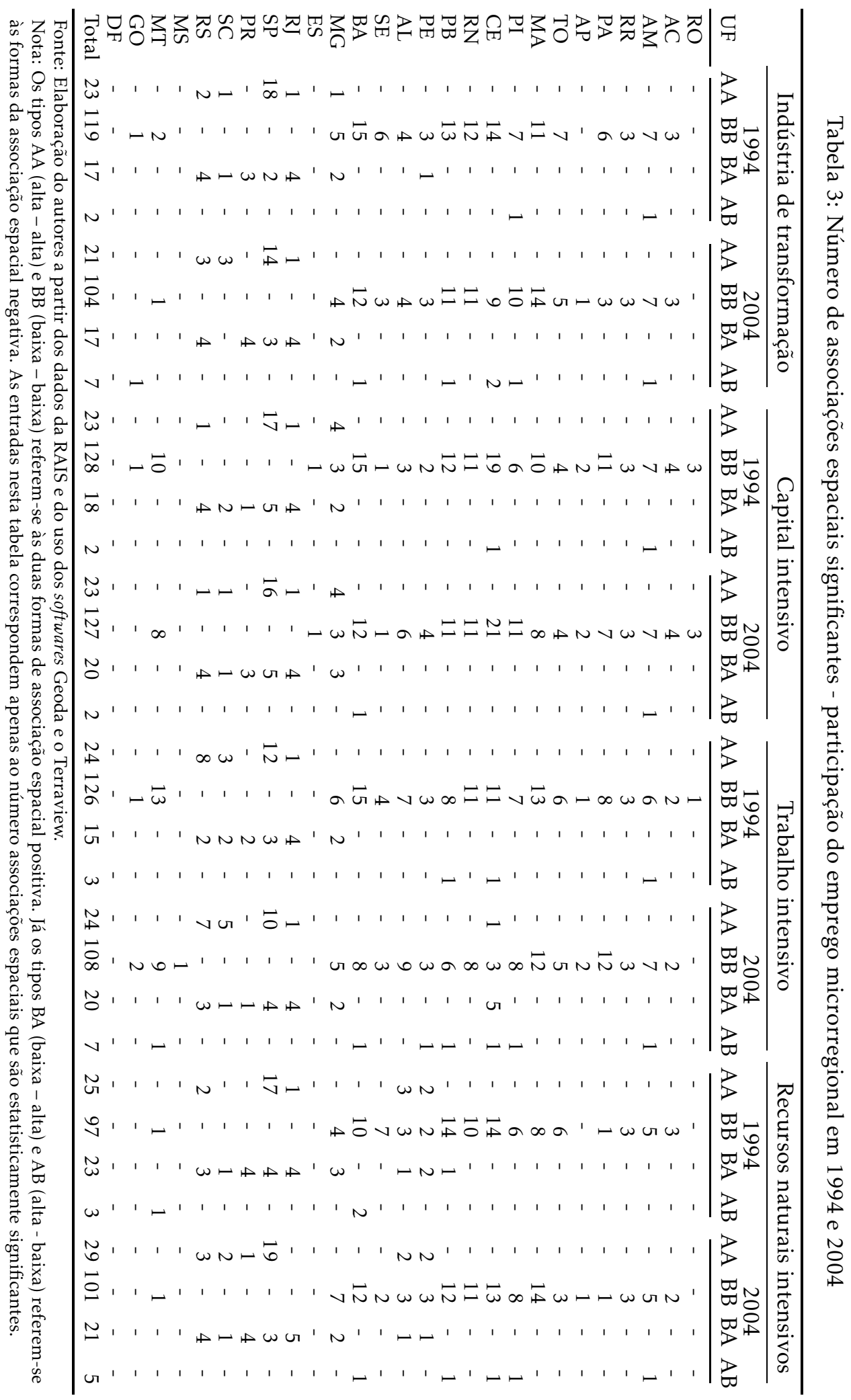


Tabela 4: Identificação de clusters por microrregiões e crescimento do emprego, segundo a indústria de transformação e os segmentos industriais - 1994 e 2004

\begin{tabular}{|c|c|c|c|c|c|c|c|c|c|}
\hline \multicolumn{5}{|c|}{ Indústria de Transformação } & \multicolumn{5}{|c|}{ Capital Intensivo } \\
\hline UF & microrregião & $\begin{array}{c}\text { taxa de } \\
\text { crescimento } \\
(1994-2004)\end{array}$ & $\begin{array}{r}\text { clus } \\
1994\end{array}$ & $\begin{array}{l}\text { ters } \\
2004\end{array}$ & UF & microrregião & $\begin{array}{c}\text { taxa de } \\
\text { crescimento } \\
(1994-2004)\end{array}$ & $\begin{array}{r}\text { clus } \\
1994\end{array}$ & $\begin{array}{l}\text { sters } \\
2004\end{array}$ \\
\hline MG & Divinópolis & 53,17 & $\checkmark$ & & MG & Sete Lagoas & 20,71 & $\checkmark$ & $\checkmark$ \\
\hline RJ & Serrana & $-35,31$ & $\checkmark$ & $\checkmark$ & MG & Pará de Minas & $-6,86$ & $\checkmark$ & \\
\hline SP & Rio Claro & 43,66 & $\checkmark$ & & MG & Itabira & $-4,46$ & $\checkmark$ & $\checkmark$ \\
\hline SP & Limeira & $-6,63$ & $\checkmark$ & $\checkmark$ & MG & Divinópolis & 24,08 & $\checkmark$ & $\checkmark$ \\
\hline SP & Piracicaba & $-1,39$ & $\checkmark$ & $\checkmark$ & MG & Pouso Alegre & 64,37 & & $\checkmark$ \\
\hline SP & Pirassununga & $-15,69$ & $\checkmark$ & & RJ & Serrana & $-43,21$ & $\checkmark$ & $\checkmark$ \\
\hline SP & Moji Mirim & 0,58 & $\checkmark$ & $\checkmark$ & SP & Limeira & 18,57 & $\checkmark$ & $\checkmark$ \\
\hline SP & Campinas & $-6,48$ & $\checkmark$ & $\checkmark$ & SP & Piracicaba & 22,41 & $\checkmark$ & $\checkmark$ \\
\hline SP & Amparo & $-2,02$ & $\checkmark$ & $\checkmark$ & SP & Moji Mirim & 53,13 & $\checkmark$ & $\checkmark$ \\
\hline SP & Tatuí & 13,25 & $\checkmark$ & & SP & Campinas & 5,97 & $\checkmark$ & $\checkmark$ \\
\hline SP & Sorocaba & $-7,44$ & $\checkmark$ & $\checkmark$ & SP & Amparo & $-4,84$ & $\checkmark$ & $\checkmark$ \\
\hline SP & Jundiaí & $-11,89$ & $\checkmark$ & $\checkmark$ & SP & Tatuí & 10,31 & $\checkmark$ & $\checkmark$ \\
\hline SP & $\begin{array}{l}\text { Bragança } \\
\text { Paulista }\end{array}$ & 9,76 & $\checkmark$ & $\checkmark$ & SP & Sorocaba & 5,55 & $\checkmark$ & $\checkmark$ \\
\hline SP & $\begin{array}{l}\text { São J. dos } \\
\text { Campos }\end{array}$ & $-3,85$ & $\checkmark$ & & SP & Jundiaí & $-1,93$ & $\checkmark$ & $\checkmark$ \\
\hline SP & Osasco & $-6,60$ & $\checkmark$ & $\checkmark$ & SP & Bragança P. & 35,20 & $\checkmark$ & $\checkmark$ \\
\hline SP & Guarulhos & $-22,80$ & $\checkmark$ & $\checkmark$ & SP & $\begin{array}{l}\text { São J. dos } \\
\text { Campos }\end{array}$ & 4,25 & $\checkmark$ & $\checkmark$ \\
\hline SP & $\begin{array}{l}\text { Itapecerica da } \\
\text { Serra }\end{array}$ & $-9,18$ & $\checkmark$ & $\checkmark$ & SP & Guaratinguetá & 27,80 & $\checkmark$ & \\
\hline SP & São Paulo & $-41,20$ & $\checkmark$ & $\checkmark$ & SP & Osasco & $-3,64$ & $\checkmark$ & $\checkmark$ \\
\hline SP & $\begin{array}{l}\text { Moji das } \\
\text { Cruzes }\end{array}$ & $-15,87$ & $\checkmark$ & $\checkmark$ & SP & Guarulhos & $-16,21$ & $\checkmark$ & $\checkmark$ \\
\hline SP & Santos & $-44,89$ & $\checkmark$ & $\checkmark$ & SP & $\begin{array}{l}\text { Itapecerica da } \\
\text { S. }\end{array}$ & $-1,45$ & $\checkmark$ & $\checkmark$ \\
\hline SC & $\begin{array}{l}\text { São Bento do } \\
\text { Sul }\end{array}$ & 7,25 & $\checkmark$ & $\checkmark$ & SP & São Paulo & $-35,98$ & $\checkmark$ & $\checkmark$ \\
\hline SC & Joinville & 5,13 & & $\checkmark$ & SP & $\begin{array}{l}\text { Moji das } \\
\text { Cruzes }\end{array}$ & $-13,85$ & $\checkmark$ & $\checkmark$ \\
\hline SC & Itajaí & 104,90 & & $\checkmark$ & SP & Santos & $-39,53$ & $\checkmark$ & $\checkmark$ \\
\hline RS & Guaporé & 89,92 & & $\checkmark$ & $\mathrm{SC}$ & Itajaí & 114,65 & & $\checkmark$ \\
\hline RS & Montenegro & 55,15 & $\checkmark$ & $\checkmark$ & RS & São Jerônimo & $-4,26$ & $\checkmark$ & $\checkmark$ \\
\hline RS & $\begin{array}{l}\text { Gramado- } \\
\text { Canela }\end{array}$ & 11,35 & $\checkmark$ & $\checkmark$ & & & & & \\
\hline
\end{tabular}


Tabela 4: Continuação

\begin{tabular}{|c|c|c|c|c|c|c|c|c|c|}
\hline \multicolumn{5}{|c|}{ Trabalho Intensivo } & \multicolumn{5}{|c|}{ Recursos Naturais Intensivos } \\
\hline UF & microrregião & $\begin{array}{c}\text { taxa de } \\
\text { crescimento } \\
(1994-2004)\end{array}$ & \multicolumn{2}{|c|}{$\begin{array}{c}\text { clusters } \\
19942004\end{array}$} & UF & microrregião & $\begin{array}{c}\text { taxa de } \\
\text { crescimento } \\
(1994-2004)\end{array}$ & \multicolumn{2}{|c|}{ clusters } \\
\hline $\mathrm{CE}$ & Pacajus & 1519,27 & & $\checkmark$ & PE & Itamaracá & 4,17 & $\checkmark$ & $\checkmark$ \\
\hline RJ & Serrana & $-36,80$ & $\checkmark$ & $\checkmark$ & $\mathrm{PE}$ & Suape & 99,92 & $\checkmark$ & $\checkmark$ \\
\hline SP & Piracicaba & $-18,04$ & $\checkmark$ & $\checkmark$ & $\mathrm{AL}$ & Serrana dos Q. & $-5,83$ & $\checkmark$ & \\
\hline $\mathrm{SP}$ & Campinas & $-5,86$ & $\checkmark$ & & $\mathrm{AL}$ & Mata Alagoana & 51,73 & $\checkmark$ & $\checkmark$ \\
\hline $\mathrm{SP}$ & Sorocaba & $-36,61$ & $\checkmark$ & $\checkmark$ & $\mathrm{AL}$ & Maceió & 67,23 & $\checkmark$ & $\checkmark$ \\
\hline SP & Jundiaí & $-29,75$ & $\checkmark$ & $\checkmark$ & SP & Jaboticabal & $-8,56$ & & $\checkmark$ \\
\hline SP & Bragança P. & $-23,22$ & $\checkmark$ & $\checkmark$ & RJ & Serrana & $-13,94$ & $\checkmark$ & \\
\hline SP & Osasco & 0,37 & $\checkmark$ & $\checkmark$ & SP & Araraquara & 1,90 & $\checkmark$ & $\checkmark$ \\
\hline $\mathrm{SP}$ & $\begin{array}{l}\text { Franco da } \\
\text { Rocha }\end{array}$ & $-31,63$ & $\checkmark$ & $\checkmark$ & SP & São Carlos & 1,91 & $\checkmark$ & $\checkmark$ \\
\hline SP & Guarulhos & $-31,74$ & $\checkmark$ & $\checkmark$ & $\mathrm{SP}$ & Rio Claro & 23,46 & $\checkmark$ & $\checkmark$ \\
\hline $\mathrm{SP}$ & $\begin{array}{l}\text { Itapecerica da } \\
\text { Serra }\end{array}$ & $-16,54$ & $\checkmark$ & $\checkmark$ & SP & Limeira & $-23,63$ & $\checkmark$ & $\checkmark$ \\
\hline $\mathrm{SP}$ & São Paulo & $-41,40$ & $\checkmark$ & $\checkmark$ & SP & Piracicaba & $-18,30$ & $\checkmark$ & $\checkmark$ \\
\hline $\mathrm{SP}$ & $\begin{array}{l}\text { Moji das } \\
\text { Cruzes }\end{array}$ & $-0,93$ & $\checkmark$ & $\checkmark$ & SP & Pirassununga & $-17,26$ & $\checkmark$ & $\checkmark$ \\
\hline SP & Santos & $-31,33$ & $\checkmark$ & & SP & Moji Mirim & $-21,91$ & $\checkmark$ & $\checkmark$ \\
\hline SC & Canoinhas & $-15,59$ & & $\checkmark$ & SP & Campinas & $-20,77$ & $\checkmark$ & $\checkmark$ \\
\hline SC & $\begin{array}{l}\text { São Bento do } \\
\text { Sul }\end{array}$ & $-0,21$ & $\checkmark$ & $\checkmark$ & SP & Amparo & 4,37 & & $\checkmark$ \\
\hline SC & Joinville & $-9,38$ & $\checkmark$ & $\checkmark$ & $\mathrm{SP}$ & Tatuí & 17,5 & & $\checkmark$ \\
\hline $\mathrm{SC}$ & Rio do Sul & 42,21 & $\checkmark$ & $\checkmark$ & $\mathrm{SP}$ & Sorocaba & $-1,13$ & $\checkmark$ & $\checkmark$ \\
\hline SC & Itajaí & 50,43 & & $\checkmark$ & $\mathrm{SP}$ & Jundiaí & $-14,06$ & $\checkmark$ & $\checkmark$ \\
\hline RS & Guaporé & 39,71 & $\checkmark$ & $\checkmark$ & $\mathrm{SP}$ & Bragança P. & 3,52 & $\checkmark$ & $\checkmark$ \\
\hline RS & Vacaria & $-28,21$ & $\checkmark$ & & SP & Osasco & $-9,23$ & $\checkmark$ & $\checkmark$ \\
\hline RS & Caxias do Sul & $-18,58$ & $\checkmark$ & $\checkmark$ & $\mathrm{SP}$ & Guarulhos & $-19,75$ & $\checkmark$ & $\checkmark$ \\
\hline RS & Lajeado-Est. & 11,02 & $\checkmark$ & $\checkmark$ & SP & $\begin{array}{l}\text { Itapecerica da } \\
\text { S. }\end{array}$ & $-8,19$ & $\checkmark$ & $\checkmark$ \\
\hline RS & Montenegro & 31,14 & $\checkmark$ & $\checkmark$ & $\mathrm{SP}$ & São Paulo & $-46,47$ & $\checkmark$ & $\checkmark$ \\
\hline RS & Gramado-Ca. & $-2,19$ & $\checkmark$ & $\checkmark$ & $\mathrm{SP}$ & Moji das C. & $-26,01$ & $\checkmark$ & $\checkmark$ \\
\hline RS & Porto Alegre & $-23,11$ & $\checkmark$ & $\checkmark$ & $\mathrm{SP}$ & Santos & $-55,46$ & $\checkmark$ & \\
\hline RS & Osório & $-2,26$ & $\checkmark$ & $\checkmark$ & PR & Ponta Grossa & 6,70 & & $\checkmark$ \\
\hline & & & & & SC & Concórdia & 41,18 & & $\checkmark$ \\
\hline & & & & & SC & Itajaí & 123,11 & & $\checkmark$ \\
\hline & & & & & RS & Guaporé & 160,58 & & $\checkmark$ \\
\hline & & & & & RS & Montenegro & 76,79 & $\checkmark$ & $\checkmark$ \\
\hline & & & & & RS & Gramado-Ca. & 39,05 & $\checkmark$ & $\checkmark$ \\
\hline
\end{tabular}

Fonte: Elaboração do autores a partir dos dados da RAIS e do uso dos softwares Geoda e Terraview. 
Tabela 5: Número de associações espaciais significantes: crescimento do emprego microrregional entre 1994 e 2004

\begin{tabular}{|c|c|c|c|c|c|c|c|c|c|c|c|c|c|c|c|c|}
\hline \multirow[b]{2}{*}{ UF } & \multicolumn{4}{|c|}{$\begin{array}{l}\text { Indústria de } \\
\text { transformação }\end{array}$} & \multicolumn{4}{|c|}{$\begin{array}{c}\text { Capital } \\
\text { intensivo }\end{array}$} & \multicolumn{4}{|c|}{$\begin{array}{l}\text { Trabalho } \\
\text { intensivo }\end{array}$} & \multicolumn{4}{|c|}{$\begin{array}{l}\text { Rec. Naturais } \\
\text { Intensivo }\end{array}$} \\
\hline & $\mathrm{AA}$ & BB & BA & $\mathrm{AB}$ & AA & $\mathrm{BB}$ & BA & $\mathrm{AB}$ & $\mathrm{AA}$ & $\mathrm{BB}$ & BA & $\mathrm{AB}$ & AA & BB & BA & $\mathrm{AB}$ \\
\hline $\mathrm{RO}$ & - & - & - & - & - & - & - & - & - & - & - & - & - & - & - & - \\
\hline $\mathrm{AC}$ & - & 1 & - & - & - & - & - & - & - & - & - & - & - & 1 & - & - \\
\hline AM & - & 2 & - & - & - & - & - & - & - & 4 & - & - & - & 3 & - & - \\
\hline RR & - & - & - & - & - & - & - & - & - & - & - & - & - & - & - & - \\
\hline PA & - & - & - & - & - & 1 & 3 & - & - & 2 & - & - & - & - & 1 & - \\
\hline $\mathrm{AP}$ & - & 1 & - & - & - & - & - & - & - & 4 & - & - & - & - & - & - \\
\hline TO & - & - & - & - & - & - & 1 & - & - & - & - & - & - & - & - & - \\
\hline MA & - & - & - & 1 & - & 2 & 4 & - & - & 2 & - & 1 & - & - & - & - \\
\hline PI & - & 1 & - & 1 & - & 8 & - & - & - & - & - & - & - & 1 & - & - \\
\hline CE & 3 & - & 7 & - & - & 2 & 1 & - & 5 & - & 8 & - & - & - & 5 & - \\
\hline RN & - & - & 3 & - & 2 & - & - & 1 & - & 1 & 2 & - & 2 & - & 5 & - \\
\hline PB & 1 & - & 5 & - & - & 2 & 5 & - & 1 & 1 & 6 & - & 3 & - & 3 & - \\
\hline PE & - & 1 & - & - & - & - & - & - & - & - & - & - & - & 2 & - & - \\
\hline $\mathrm{AL}$ & - & 1 & - & - & - & 4 & - & - & - & 4 & - & 1 & - & 1 & 3 & - \\
\hline SE & 1 & - & 4 & - & - & 1 & - & - & 1 & - & 2 & - & - & - & 1 & - \\
\hline BA & - & - & - & - & - & - & - & 1 & 3 & - & 6 & - & - & 2 & - & - \\
\hline MG & - & 8 & - & - & 3 & 2 & 5 & - & 2 & 1 & 1 & - & - & 4 & - & - \\
\hline ES & - & - & - & - & - & - & - & - & - & - & - & - & - & 1 & - & - \\
\hline RJ & - & 7 & - & - & - & 2 & 1 & - & - & 3 & - & - & - & 10 & - & - \\
\hline SP & - & 28 & - & - & - & 4 & - & - & - & 17 & - & - & - & 26 & - & - \\
\hline PR & - & 4 & - & - & - & - & - & - & - & - & - & 1 & - & 1 & - & - \\
\hline SC & - & 3 & - & - & - & - & 1 & - & - & 3 & - & - & - & 2 & - & - \\
\hline RS & - & 12 & - & - & - & 2 & - & - & - & 14 & - & - & - & 6 & - & - \\
\hline MS & - & - & - & - & 2 & - & - & - & - & - & - & - & - & - & - & - \\
\hline MT & 4 & - & 1 & - & 1 & - & 1 & 1 & - & - & - & - & 3 & - & 3 & - \\
\hline GO & - & - & - & - & - & - & 1 & - & - & - & - & - & - & - & - & - \\
\hline DF & - & - & - & - & - & - & 1 & - & - & - & - & - & - & - & - & - \\
\hline Total & 9 & 69 & 20 & 2 & 8 & 30 & 24 & 3 & 12 & 56 & 25 & 3 & 8 & 60 & 21 & 0 \\
\hline \multicolumn{17}{|c|}{$\begin{array}{l}\text { Fonte: Elaboração dos autores a partir dos dados da RAIS e do uso dos softwares Geoda e } \\
\text { terraview. }\end{array}$} \\
\hline & & & & & & & & & & & & & & & & \\
\hline
\end{tabular}


Tabela 6: Identificação de clusters de crescimento por microrregiões, indústria de transformação e segmentos industriais entre 1994 e 2004

\begin{tabular}{|c|c|c|c|c|}
\hline \multicolumn{2}{|c|}{ sigla_uf nome_micro } & \multicolumn{3}{|c|}{$\begin{array}{lll}\text { participação_1994 participação_2004 } & \text { crescimento } \\
\text { do emprego } & \text { do emprego } & \text { do emprego }\end{array}$} \\
\hline \multicolumn{5}{|c|}{ Clusters de crescimento da indústria de transformação } \\
\hline $\mathrm{CE}$ & Itapipoca & 0,00863 & 0,04156 & 381,58 \\
\hline $\mathrm{CE}$ & Uruburetama & 0,00915 & 0,06162 & 573,44 \\
\hline $\mathrm{CE}$ & Baixo Jaguaribe & 0,01959 & 0,10415 & 431,65 \\
\hline PB & Piancó & 0,00004 & 0,00034 & 762,16 \\
\hline SE & $\begin{array}{l}\text { Nossa Senhora } \\
\text { das Dores }\end{array}$ & 0,00022 & 0,00138 & 530,14 \\
\hline MT & Alto Teles Pires & 0,01363 & 0,06572 & 382,17 \\
\hline MT & Canarana & 0,00247 & 0,01749 & 608,10 \\
\hline MT & Rosário Oeste & 0,00016 & 0,00117 & 635,85 \\
\hline MT & $\begin{array}{l}\text { Primavera do } \\
\text { Leste }\end{array}$ & 0,00104 & 0,01841 & 1670,19 \\
\hline \multicolumn{5}{|c|}{ Clusters de crescimento do segmento capital intensivo } \\
\hline RN & Pau dos ferros & 0,00005 & 0,00022 & 382,46 \\
\hline $\mathrm{RN}$ & Seridó Ocidental & 0,00237 & 0,02536 & 970,04 \\
\hline MG & Teófilo Otoni & 0,00059 & 0,00484 & 716,19 \\
\hline MG & Guanhães & 0,00009 & 0,00141 & 1446,05 \\
\hline MG & Peçanha & 0,00005 & 0,00040 & 768,42 \\
\hline MS & Alto Taguari & 0,00255 & 0,01594 & 525,10 \\
\hline MS & Cassilândia & 0,00023 & 0,00220 & 864,91 \\
\hline MT & Rondonópolis & 0,00985 & 0,04490 & 355,84 \\
\hline \multicolumn{5}{|c|}{ Clusters de crescimento do segmento trabalho intensivo } \\
\hline $\mathrm{CE}$ & Santa Quitéria & 0,00008 & 0,00146 & 1656,92 \\
\hline $\mathrm{CE}$ & Baixo Curu & 0,00241 & 0,02073 & 760,17 \\
\hline $\mathrm{CE}$ & Cascavel & 0,00341 & 0,13774 & 3939,30 \\
\hline $\mathrm{CE}$ & Litoral do Aracati & 0,00091 & 0,03788 & 4044,42 \\
\hline $\mathrm{CE}$ & Médio Jaguaribe & 0,00058 & 0,01377 & 2265,98 \\
\hline PB & Guarabira & 0,00748 & 0,05245 & 601,20 \\
\hline SE & Tobias Barreto & 0,00067 & 0,01815 & 2629,32 \\
\hline BA & Jacobina & 0,00399 & 0,02470 & 519,05 \\
\hline BA & $\begin{array}{l}\text { Vitória da } \\
\text { Conquista }\end{array}$ & 0,01530 & 0,10774 & 604,18 \\
\hline BA & Porto Seguro & 0,00856 & 0,08073 & 843,11 \\
\hline MG & Salinas & 0,00083 & 0,01119 & 1246,57 \\
\hline MG & Almenara & 0,00042 & 0,00311 & 647,60 \\
\hline \multicolumn{5}{|c|}{ Clusters de crescimento do segmento recursos naturais intensivos } \\
\hline $\mathrm{RN}$ & Angicos & 0,00025 & 0,00375 & 1424,39 \\
\hline RN & Agreste Potiguar & 0,00191 & 0,02828 & 1380,63 \\
\hline PB & Piancó & 0,00012 & 0,00099 & 702,44 \\
\hline PB & $\begin{array}{l}\text { Seridó Oriental } \\
\text { Paraibano }\end{array}$ & 0,00148 & 0,00686 & 363,51 \\
\hline $\mathrm{PB}$ & Cariri Ocidental & 0,00062 & 0,00405 & 557,47 \\
\hline MT & Canarana & 0,00567 & 0,04116 & 625,93 \\
\hline MT & Rosário Oeste & 0,00049 & 0,00336 & 581,54 \\
\hline MT & $\begin{array}{l}\text { Primavera do } \\
\text { leste }\end{array}$ & 0,00185 & 0,02053 & 1009,73 \\
\hline
\end{tabular}

Fonte: Elaboração dos autores a partir dos dados da RAIS e do uso dos softwares Geoda e Terraview. 
em termos do crescimento das participações do emprego e com fortes encadeamentos econômicos situam-se em alguns estados pertencentes às regiões Nordeste e Centro-Oeste do país e no estado de Minas Gerais.

Cabe registrar, ainda, a ausência de microrregiões da região Sul e, sobretudo, daquelas pertencentes aos estados de São Paulo e Rio de Janeiro, na identificação de clusters de crescimento do tipo AA, conforme as informações apresentadas nas Tabelas 5 e 6. Por outro lado, as microrregiões da região Nordeste têm forte presença na lista dos clusters AA, com maior incidência no segmento trabalho intensivo, consistente com o surgimento de novos polos industriais nesta região e com a relocalização industrial no país no sentido do aproveitamento das vantagens comparativas locais na região.

\section{Determinantes do Crescimento do Emprego Industrial}

Os diversos argumentos para explicar a aglomeração das atividades no espaço são fundamentados por teorias diferentes. Por esse motivo, este trabalho usa o modelo empírico da demanda por trabalho das firmas para estimar os efeitos dos determinantes econômicos sobre o crescimento do emprego. Seguem, adiante, os aspectos metodológicos desta parte do trabalho. A seguir, apresentam-se os resultados estimados para o crescimento do emprego da indústria de transformação para o período entre 1994 e 2004.

\subsection{Modelo Empírico}

Para verificar os efeitos dos determinantes econômicos, tais como custos de transporte e das variáveis de concentração inicial de recursos, sobre o crescimento do emprego industrial brasileiro, este estudo segue o modelo empírico adotado por Hanson (1998). Assim, a partir do processo de maximização de lucro das firmas e por meio da proposição de Hottelling, a demanda por trabalho na unidade geográfica $i$ pela uma indústria $j$ é dada por:

$$
L_{i j}=-\frac{\partial \Pi_{j}\left(R_{i j}, p_{j}, \xi_{i j}\right)}{\partial w_{i j}},
$$

onde $\Pi_{j}\left(\right.$ ) é a função lucro, $L_{i j}$ é o emprego na região $i$ da indústria $j, R_{i j}$ é um vetor de preços de fatores para $i j, p_{j}$ é o preço nacional do produto da indústria $j, \xi_{i j}$ é um vetor de efeitos externos, tais como as economias de aglomeração e as externalidades pecuniárias ou linkages verticais e, por fim, $w_{i j}$ é o salário.

Aplicando-se o logarítmico e depois colocando a equação (2) em termos do crescimento $^{14}$ das variáveis, tem-se a seguinte expressão:

$$
\Delta \ln \left(L_{i j t}\right)=\alpha+\theta \Delta \ln \left(w_{i j t}\right)+\sum_{h=1}^{H} p_{h} \Delta \ln \left(r_{i j t}^{h}\right)+\gamma \Delta \ln \left(p_{j t}\right)+\phi \Delta \ln \left(\xi_{i j t}\right),
$$

\footnotetext{
${ }^{14}$ Lembre-se de que outros efeitos podem afetar o processo de aglomeração das atividades, tais como os recursos naturais. A identificação dos efeitos externos em comparação com aqueles fatores não observáveis num determinado momento do tempo é por certo indistinguível. Para evitar tal problema de identificação, este estudo estima uma equação de crescimento do emprego, uma vez que, se os efeitos externos são de natureza dinâmica, eles afetam o crescimento.
} 
onde $\Delta$ é o operador de diferença e os $r_{i j}^{h}$ são os preços dos outros fatores, exceto trabalho. A equação (3) mostra que, para um dado nível de preço dos fatores e do produto, o crescimento dos efeitos externos aumenta a demanda por trabalho industrial estadual.

Como a hipótese sobre externalidades pecuniárias é que o crescimento do emprego é mais elevado em localidades, que apresentam maior concentração de firmas fornecedoras e compradoras de insumos intermediários, e que economias de aglomeração são função da concentração geográfica inicial da indústria, então, seguindo esta linha de raciocínio, no modelo é assumido que o crescimento dos efeitos externos depende das condições iniciais da concentração de recursos numa dada localização. Sendo assim, os efeitos externos podem ser expressos como função dos níveis iniciais de concentração industrial, dado por:

$$
\Delta \ln \left(\xi_{i j t}\right)=a+\sum_{n=1}^{N} b_{n} \ln \left(x_{i j t-1}^{n}\right)+\varepsilon_{i j t},
$$

onde os $x_{i j t-1}^{n}$ são as fontes de concentração que geram os efeitos externos, com Nsendo o número total de tais efeitos e $\varepsilon_{i j t}$ o termo de erro. Sendo assim, o primeiro tipo de efeito externo são os linkages para frente e para trás do mercado ou externalidades pecuniárias, relacionadas à Venables (1996). São consideradas, também, duas fontes de economias de aglomeração. A primeira delas mede a aglomeração dentro da indústria e a segunda entre indústrias diferentes, medida pela diversidade industrial. Conforme o Capítulo 2, a primeira fonte é remetida às teorias MAR e ao estudo de Fujita e Thisse (2002), enquanto a segunda está associada às ideias de Jacobs (1969) e incorporada no modelo de Fingleton (2003).

Por fim, para identificar os fatores específicos à localização, que afetam o crescimento do emprego, é necessário controlar os efeitos setoriais, descontando, então, os efeitos agregados. Assim, expressa a equação (3) em temos de desvio da média ponderada da indústria nacional. Supondo também que apenas o preço do trabalho é que varia entre estados, eliminam-se os preços do produto e dos outros fatores, exceto o da mão-de-obra, naquela expressão. Assim, a equação torna-se:

$$
\Delta \ln \left(\frac{L_{i j t}}{L_{j t}}\right)=\theta \Delta \ln \left(\frac{w_{i j t}}{\bar{w}_{j t}}\right)+\sum_{l=1}^{L} \beta_{l} \ln \left(\frac{x_{i j t-1}^{l}}{x_{j t-1}^{\bar{l}}}\right)+\varepsilon_{i j t}-\bar{\varepsilon}_{j t},
$$

onde a expressão da equação (5) será usada para as estimações. Adiante, serão definidas as variáveis utilizadas. Com essas definições e dada a expressão para (5), é possível obter a equação a ser estimada, a qual é expressa por (6) e (7), apresentadas a seguir. Estas mostram o crescimento do emprego relativo como função das condições iniciais da indústria de transformação estadual relativa ou ponderada pela indústria nacional ${ }^{15}$.

\footnotetext{
15 Subjacente à análise está à hipótese de mobilidade locacional do fator trabalho, com as firmas locais dispondo de oferta de trabalho em escala nacional. Note-se que a identificação dos efeitos na equação (5) seria ainda possível com uma oferta de trabalho menos elástica desde que os efeitos derivados da aglomeração das atividades impactassem exclusivamente nas conduções de demanda por trabalho
} 


\subsection{Definição das Variáveis e Fontes dos Dados}

Em relação às definições das variáveis, a dependente - crescemp - procura captar o crescimento médio do emprego industrial estadual relativo à indústria nacional. O primeiro termo do lado direito da equação (6) - "salmedio" mensura o salário ${ }^{16}$ anual por trabalhador do período inicial relativo à média nacional. Segundo o argumento neoclássico, espera-se que, para iguais condições no que diz respeito aos demais fatores nas localidades, o crescimento relativo do emprego relaciona-se de forma decrescente com o salário relativo inicial $^{17}$.

A segunda variável da equação - "estmedio" - informa a respeito do tamanho médio do estabelecimento, calculado pelo número de trabalhadores por estabelecimento na indústria estadual relativo à indústria nacional. Como sugerido por Hanson (1998) e Glaeser et al. (1992), isso procura controlar as diferenças na tecnologia e competição. Da forma como está mensurada tal medida para este trabalho, espera-se uma associação decrescente com o crescimento do emprego, já que menores valores para esta variável significam que as firmas daquela indústria e naquele local são menores do que elas são na média para o Brasil. Em outras palavras, a indústria local é mais competitiva do que em outro lugar do país.

As variáveis dadas do terceiro até o quinto termo da equação (6) mensuram os canais pelos quais podem atuar as economias externas, as quais refletem o comportamento inicial do ambiente industrial que, de acordo com os modelos da economia regional e urbana, afetam o crescimento do emprego. A primeira delas - "conexões" - é utilizada para captar os efeitos para trás e para frente no mercado, o que é feito a partir de uma medida do grau de concentração de indústrias compradoras e vendedoras, dentro do grupo de indústrias de dois dígitos a que pertence a indústria em questão. Ou seja, esta variável apreende os benefícios gerados para as firmas por elas estarem localizadas próximas às outras empresas, as quais formam seus mercados demandantes e fornecedores de insumos e produtos.

Assim, e seguindo Hanson (1998), a medida de "conexões" é obtida tomando-se o estoque inicial do emprego estadual da indústria de dois dígitos em relação ao emprego industrial estadual de três dígitos, ajustada pelo estoque inicial de emprego da indústria nacional de dois dígitos relativo ao emprego da indústria nacional de três dígitos. A ideia é que quanto maior tal medida, maior a densidade no estado em relação ao grupo particular de dois dígitos e, assim, maior a disponibilidade de ofertantes e demandantes para a firma considerada (três dígitos). De acordo com o modelo teórico dos linkages verticais de Venables (1996), espera-se que em estados, em que a concentração de indústrias demandantes e ofertantes seja maior, o crescimento do emprego também seja maior.

Os outros dois termos refletem as externalidades dinâmicas ou as economias de aglomeração. A primeira delas parte dos argumentos das teorias MAR e está microfundamenta no estudo de Fujita e Thisse (2002). Esta variável é designada, então, pelo termo "aglomdentro" e mensura a concentração de fir-

\footnotetext{
16 Seguindo Hanson (1998), para evitar o problema de simultaneidade na regressão, optou-se pela utilização do salário médio do período inicial, ao invés de mudança no salário relativo.

17 Está é uma explicação para a localização industrial da teoria neoclássica e serve, aqui, como um controle, uma vez que tal efeito poderia estar atuando através das demais variáveis, o que comprometeria as estimativas.
} 
mas numa mesma indústria, desta forma, tenta captar os efeitos de transbordamentos do conhecimento dentro da indústria em questão. Do mesmo modo como em Hanson (1998), ela é calculada ${ }^{18}$ pela participação do emprego de uma determinada indústria $j$, no total da indústria estadual, relativa à participação do emprego dessa mesma indústria, no total industrial nacional. Espera-se que essa medida de especialização ou de externalidade dentro da indústria seja positivamente correlacionada com o crescimento do emprego.

Enquanto o quinto termo do lado direito da equação (6) - "diversidade" industrial relativa - mede a aglomeração entre indústrias diferentes ou a diversidade industrial, ou seja, tenta captar os efeitos de transbordamento do conhecimento fora da indústria em questão, conforme os trabalhos de Jacobs (1969) e Fingleton (2003). De acordo com Hanson (1998), a variável diversidade industrial é mensurada pelo somatório do quadrado das participações do emprego estadual para as outras indústrias, ponderada por essa mesma participação em nível nacional ${ }^{19}$. Quanto mais distribuído o emprego estadual (nacional) entre as indústrias, menor é a soma do quadrado das participações do emprego estadual (nacional). E quanto menor é a razão entre a participação quadrada do emprego estadual e a participação quadrada do emprego nacional, mais diversa é a indústria estadual em relação à nacional. Assim, espera-se que esta variável seja negativamente correlacionada com o crescimento do emprego, o que indica externalidades positivas geradas pela diversidade industrial.

Por fim, o sexto termo do lado direito da equação expressa uma medida proxy para custos de transporte que entram como um controle. Como observado no Capítulo 2 do presente trabalho, existem forças que favorecem a aglomeração das atividades econômicas e outras forças que atuam no sentido contrário, favorecendo a dispersão. Além disso, a potência destas forças depende do nível dos custos de transporte e numa situação, em que estes são elevados, tem-se como possível resultado a dispersão destas atividades. Portanto, isto torna necessário o uso do controle de tal variável.

Para mensurar essa variável leva-se em conta a distância rodoviária de cada mercado, ou melhor, o somatório das distâncias entre capitais dos estados. A medida das distâncias estaduais também está ponderada pela participação do emprego estadual da indústria no total nacional desta indústria, da qual o produto é transportado, dado pelo termo $w_{i j t}$. Seguindo Hanson (1998), esta ponderação tenta captar as condições da infra-estrutura local, de modo que quanto maior é aquele termo para uma localidade, maior a concentração local daquela indústria, o que poderia estar refletindo uma melhor infra-estrutura local disponível para o transporte dos bens para as demais localidades. Sendo assim, quanto mais concentrada for uma indústria específica em um estado, maior o denominador desta expressão e, portanto, menor será o valor da variável "distmercado". Por outro lado, distâncias maiores para os outros mercados aumentam o valor da expressão. O impacto desta variável, em geral, depende da intensidade das forças aglomerativas e do nível inicial de concentração.

Assim, o modelo a ser estimado pode ser expresso pelas equações (6) e (7), seguir:

\footnotetext{
${ }^{18}$ A variável está mensurada da mesma forma como a medida de localização tradicionalmente usada na economia regional. Ver a esse respeito Haddad (1989).

${ }^{19} \mathrm{O}$ termo quadrático incluído nesta medida faz com que aumente a amplitude de variação de cada valor obtido.
} 


$$
\begin{aligned}
\Delta \ln \left(\frac{L_{i j t}}{L_{j t}}\right)=\beta_{0}+ & \beta_{1} \ln \left(\frac{S A L_{i j t} / L_{j t}}{S A L_{j t} / L_{j t}}\right)+ \\
& +\beta_{2} \ln \left(\frac{L_{i j t} / E S T_{i j t}}{L_{j t} / E S T_{j t}}\right)+\beta_{3} \ln \left(\frac{L_{i k t} / E S T_{i k t}}{L_{k t} / L_{j t}}\right)+ \\
+ & \beta_{4} \ln \left(\frac{L_{i j t} / E S T_{j t}}{L_{i t} / L_{t}}\right)+\beta_{5} \ln \left[\frac{\sum_{l \neq j}\left(L_{i l t} / E S T_{i t}\right)^{2}}{\sum_{l \neq j}\left(L_{l t} / E S T_{t}\right)^{2}}\right]+ \\
& +\beta_{6} \ln \left[\frac{\sum_{i \neq g} d i s t_{i g}}{\sum_{i j}\left(\omega_{i j t} \times \sum_{i \neq g} \text { dist }_{i g}\right)}\right]+\varepsilon_{i j t}
\end{aligned}
$$

crescemp $=\beta_{0}+\beta_{1}$ salmedio $+\beta_{2}$ estmedio $+\beta 3$ conexões +

$+\beta 4$ aglomdentro $+\beta_{5}$ diversidade $+\beta_{6}$ distmercado + termo de erro

nas quais: $i$ indexa os estados; $j$ indexa os grupos de indústrias de três dígitos da Classificação Nacional das Atividades Econômicas - CNAE; $k$ indexa as divisões de indústrias de dois dígitos da CNAE, a qual $j$ pertence; $t$ indexa o período de tempo final e inicial; $L$ é o estoque do emprego; $S A L$ é o salário total no ano $t$, expresso em Reais (R\$) de dezembro de 2004; EST é o número de estabelecimento das firmas; dist é a distância mensurada em $\mathrm{Km}$ da capital do estado $i$ para a de $g$, e $\omega_{i j t}=L_{i j t} / L_{j t}$.

Em relação aos dados utilizados neste trabalho, a maior parte deles - relativa às variáveis estoque de emprego ${ }^{20}$, salário total e número de estabelecimento - foi coletada por meio da base de dados da Relação Anual de Informações Sociais - RAIS, publicada pelo Ministério do Trabalho e Emprego - MTE. Já os dados das distâncias rodoviárias entre as capitais dos estados brasileiros são do Departamento Nacional de Infra-Estrutura de Transporte - DNIT e também disponíveis no Guia Turístico Quatro Rodas e no site de busca www.aondefica.com. Por fim, os dados entram na regressão na forma cross-section com 2.673 observações por cada variável, obtidas de 99 grupos de indústria potencialmente presentes nos 27 estados do Brasil ${ }^{21}$. Contudo, nem todo grupo de indústria estava presente em todas as unidades federativas, seja em função de que determinada indústria $j$ inexistia no ano inicial, mas estava presente no ano final ou vice-versa, seja também em razão dela não existir em ambos os períodos.

\subsection{Evidências para a Indústria de Transformação no Período 1994-2004}

Esta seção apresenta evidências da influência dos determinantes econômicos, tais como economias de aglomeração, linkages intersetoriais e custos de transporte, sobre o crescimento do emprego industrial. A unidade de observação

\footnotetext{
${ }^{20}$ Em razão da necessidade de se obter o estoque do emprego em anos distintos para o cálculo do crescimento do emprego e em função da mudança da CNAE/95 para a CNAE 1.0 (2002), foi necessário realizar a compatibilização das atividades industriais. Isto foi feito por meio da correspondência entre estas classificações, disponível no site do IBGE.

21 Dada à natureza destes dados, com várias observações por indústria, não é possível, para este trabalho, a utilização da análise espacial nas regressões, já que este procedimento requer que as medidas sejam agregadas em unidades geográficas.
} 
Tabela 7: Determinantes do crescimento do emprego no período 1994 2004: indústria de transformação

\begin{tabular}{lcccc}
\multicolumn{5}{l}{ Variável dependente - logarítmico do crescimento relativo do emprego } \\
\hline Variáveis Explicativas & $(1 . \mathrm{a})$ & $(1 . \mathrm{b})$ & $(2 . \mathrm{a})$ & $(2 . \mathrm{b})$ \\
\hline ln_salmedio & $0.0453^{* *}$ & $0.1329^{* *}$ & 0.0244 & $0.1541^{* *}$ \\
& $(0.0552)$ & $(0.0681)$ & $(0.0552)$ & $(0.0654)$ \\
ln_estmedio & $-0.5040^{*}$ & $-0.6088^{*}$ & $-0.3241^{*}$ & $-0.3882^{*}$ \\
& $(0.0366)$ & $(0.0396)$ & $(0.0446)$ & $(0.0573)$ \\
ln_conexões & - & - & $0.1944^{*}$ & $0.2197^{*}$ \\
& & & $(0.0354)$ & $(0.0371)$ \\
ln_aglomdentro & - & - & -0.0576 & -0.0601 \\
ln_diversidade & - & & $-0.0345)$ & $(0.0438)$ \\
distmercado & & & $-0.0302^{* *}$ & $-0.7041^{*}$ \\
& $\left(0.5291^{* *}\right.$ & $-4.2542^{* *}$ & $0.5073^{*}$ & $-4.1413^{* *}$ \\
constante & -0.5248 & $(2.3029)$ & $(0.1266)$ & $(2.1820)$ \\
& $(0.1276)$ & $(2.0438)$ & $-0.6019^{*}$ & 1.0122 \\
dummy de estado & não & sim & não & nim \\
dummy de indústria & não & sim & não & sim \\
R2 Ajustado & 0.2243 & 0.321 & 0.2562 & 0.351 \\
observações & 1888 & 1888 & 1888 & 1888 \\
\hline
\end{tabular}

Fonte: Estimação dos autores a partir dos dados da RAIS, IBGE e DNIT.

Nota: * e ${ }^{* *}$ indicam a significância estatística a 1\% e 5\%, respectivamente. O desvio padrão é destacado entre parênteses e as regressões estão com correção para heteroscedasticidade (Matriz de White).

é a indústria em uma unidade da federação. Estima-se, assim, a partir da equação (6), o crescimento do emprego dessas indústrias estaduais, no período entre os anos de 1994-2004, como função dos argumentos econômicos, medidos no ano inicial (1994). Os resultados obtidos são expostos na Tabela 7, a seguir. As estimações reportadas nas colunas (a) não incluem variáveis dummies para estado e indústria na regressão, ao passo que as das colunas (b) consideram a inclusão de uma variável dummy para cada estado e para cada grupo de indústria constados nos dados (controle dos efeitos fixos). Com isso, nesse segundo modelo, tenta-se captar as características específicas omitidas, peculiares a cada estado ou indústria.

Além disso, também se optou por estimar uma equação sem incluir as variáveis de efeitos externos, tais como as economias de aglomeração e as conexões para trás e para frente do mercado, com ou sem a presença dos efeitos fixos - dados pelos resultados das colunas (1.a) e (1.b), captando-se apenas o impacto do argumento associado à NGE - custo de transporte - e das demais variáveis de controle sobre o crescimento da demanda de emprego estadual - competição local ou escala da firma e salários. No segundo conjunto de equações, estimaram-se, além das variáveis de controles já contidas nos dois modelos anteriores, as variáveis que captam os efeitos externos - dados pelos resultados das colunas (2.a) e (2.b) - novamente, controlados ou não pelos efeitos fixos.

Em relação aos resultados, percebe-se que o salário relativo médio inicial 
está positivamente correlacionado com o crescimento relativo do emprego. De fato, das quatro regressões estimadas, o coeficiente da variável "salmedio" é estatisticamente significante a $5 \%$ nas equações (1.b) e (2.b), embora não apresente significância estatística relevante em (1.a) e (2.a), de acordo com os padrões aceitáveis. Essa relação positiva poderia sugerir que o emprego cresce mais rápido em localidades onde o tamanho do mercado é grande, consistente com o efeito de acesso ao mercado, uma das forças de aglomeração da NGE. Nota-se pelos dados da coluna (2.b), que a elasticidade salário em relação ao crescimento do emprego é de 0,1541 , implicando que um acréscimo de $1 \%$ no coeficiente da variável salários eleva a variável dependente em pouco mais de $15 \%$. Destaca-se ainda que, à medida que se incluem as variáveis de efeitos externos com controle dos efeitos fixos, o parâmetro da variável "salmedio" melhora tanto em magnitude (15,96\%), quanto em nível de significância.

Para a variável tamanho relativo do estabelecimento, o crescimento relativo do emprego é mais alto onde o tamanho relativo do estabelecimento é menor, consistente com o sinal negativo de seu coeficiente. Ou seja, estados que possuem firmas industriais menores apresentam crescimento maior. Esta evidência empírica também foi encontrada por Hanson (1998), para a indústria mexicana, e Glaeser et al. (1992), para as indústrias americanas. O resultado também é consistente com as interpretações de Porter (1990) e Jacobs (1969), em que a competição local acelera o crescimento, uma vez que, num ambiente competitivo, a inovação e a imitação são estimuladas. Com relação ao efeito quantitativo da variável, quando se observa os resultados da coluna (2.b), o valor da elasticidade obtida para a variável significa que crescimento do emprego aumenta em quase 39\%, à medida que diminui em $1 \%$ o coeficiente da variável "estmedio". Vale ressaltar também que a magnitude do parâmetro aumenta, em valor absoluto, à medida que se controla por efeitos fixos, em $20,79 \%$, sem o uso das variáveis de efeitos externos, e em $19,78 \%$, quando se faz uso destas variáveis. Porém, ele diminui quando se acrescentam as variáveis de efeitos externos em $35,69 \%$, sem controle dos efeitos fixos, e reduz em $36,24 \%$, com este controle. Esses resultados sugerem, então, que o efeito desta variável é influenciado pelas especificidades locais elou setoriais.

As estimativas registradas para a variável "distmercado" nas colunas (1.b) e (2.b) revelam correlação negativa entre a variável "distmercado" e crescimento do emprego, sendo estatisticamente significantes a $6,5 \%$ e 5,8\%, na ordem. Tal resultado sugere que, no período em questão, quando são controlados os demais efeitos, inclusive para aqueles fixos, o crescimento do emprego estadual da indústria de transformação do Brasil é menor quando os custos de transporte dos bens para as demais localidades são mais elevados, fato que estaria favorecendo a dispersão de tais atividades. Por outro lado, as evidências obtidas também revelam correlação positiva entre esta variável ("distmercado") e o crescimento do emprego, sendo estatisticamente significantes em nível de 1\% para as estimativas apresentadas nas colunas (1.a) e (1.b), porém, aqui, não são descontados os efeitos específicos de cada localidade elou indústria. Percebe-se, também, pelos dados constantes em (2.b), que um aumento de 1 (um) no valor absoluto desta variável explicativa provoca uma variação relativa de $-4,14$ no crescimento do emprego. Cabe ainda observar que o uso do controle dos efeitos fixos, além de mudar o sinal da variável, altera as magnitudes dos coeficientes obtidos. Mais uma vez isto pode sugerir que o efeito da variável recebe influência das especificidades locais e $\backslash$ ou setoriais. 
Em relação às variáveis de efeitos externos, o estudo revela evidências de que as externalidades "pecuniárias" afetam o crescimento das indústrias estaduais no período analisado. De fato, o coeficiente da variável linkages é positivo e estatisticamente significante a $1 \%$, aumentando sua magnitude em $13,01 \%$, quando os efeitos fixos são inclusos. A partir dos resultados expostos na coluna (2.b), percebe-se que um aumento em $1 \%$, na variável "conexões", eleva o crescimento do emprego em quase $22 \%$. Novamente, o efeito quantitativo da variável em questão é influenciado pelas especificidades locais e $\backslash$ ou setoriais. Estes resultados sugerem, assim, que as localidades com muitas indústrias demandantes atraem as indústrias ofertantes de insumos - efeito para trás ou de demanda - e que as firmas produtoras do bem final terão redução de custos, se estiverem localizadas onde existem relativamente muitas indústrias fornecedoras de insumos intermediários - efeito para frente ou de custo -, portanto, isso é consistente com as duas forças de aglomeração das atividades propostas no modelo de Venables (1996) dos linkages verticais.

Os resultados indicam também a influência das externalidades dinâmicas sobre o crescimento das indústrias estaduais. Com efeito, as estimativas apontam na direção de presença de spillovers tecnológicos entre indústrias, mas não dentro da indústria ${ }^{22}$. Esse resultado encontrado para a indústria estadual difere daquele obtido por Chagas e Júnior (2003), que registraram associação positiva entre uma medida de especialização das atividades e o crescimento das cidades brasileiras, no período de 1980 a 1991. A título de sugestão, essa discordância pode ser em função das diferenças na metodologia de cálculo e na unidade geográfica utilizadas.

Já a concentração de firmas entre indústrias diferentes, mensurada pela variável "diversidade", parece afetar o crescimento relativo do emprego. De fato, os resultados obtidos indicam que este é mais alto, onde existem localidades com maior variedade e diversidade industrial, o que é coerente com o sinal negativo do coeficiente estimado da variável diversidade e, portanto, consistente com os argumentos teóricos propostos por Jacobs (1969) e Fingleton (2003). Destaca-se também o crescimento do coeficiente desta variável em cerca de $2231,46 \%$ ou elasticidade 22,31 vezes maior, quando se incluem os efeitos fixos no modelo, sugerindo que seu efeito quantitativo pode diferir por setor industrial e por unidade espacial.

Os resultados apresentados para as externalidades dinâmicas, de forma geral, são próximos das análises de estudos internacionais. De fato, as evidências obtidas corroboram parte dos resultados obtidos em Hanson (1998), para os estados mexicanos, e, em Glaeser et al. (1992), para a economia americana. Mais especificamente, seus estudos também não encontram evidências favoráveis a respeito da importância da aglomeração dentro da indústria para o crescimento do emprego. Por outro lado, em relação à variável diversidade industrial, embora os resultados não corroborem as evidências presentes no primeiro dos referidos trabalhos, estes estão de acordo com as evidências presentes no segundo. As estimações obtidas aqui para a variável "diversidade" também vão ao encontro daquelas geradas por Galinari (2006) para as cidades de São Paulo.

Por fim, cabe aqui fazer uma síntese dos principais resultados obtidos. Em

\footnotetext{
22 Como destaca Glaeser et al. (1992) e Henderson (2003), existem outros motivos para a especialização regional que não as externalidades dinâmicas, tais como fontes de recursos naturais, consistentes com a teoria tradicional.
} 
relação à amostra total, as estimações da regressão cross section para a indústria de transformação revelam que, consistentes com as teorias da NGE, as externalidades pecuniárias, as quais são resultantes da proximidade dos mercados compradores e fornecedores da indústria, salários e custos de transporte, afetam o crescimento do emprego. Este também é influenciado pelas externalidades dinâmicas, particularmente, aquelas geradas da interação entre as firmas de indústrias diferentes, condizentes, então, com as ideias de Jacobs, e pela variável de competição local, que está de acordo com as teorias de Jacobs e Porter.

Contudo, na análise anterior, o período utilizado pode ser longo para analisar os efeitos dos argumentos de aglomeração, além de ser marcado por quatro passagens de governos. Para averiguar se os efeitos dos determinantes econômicos sobre o crescimento do emprego não são específicos ao período ou à escolha dos anos polares, divide-se o período de tempo em duas fases, 19941999 e 1999-2004, e estima-se, novamente, o modelo através de uma regressão em pooling, incluindo na amostra as observações para esses dois conjuntos de períodos. A Tabela 8 , a seguir, exibe os resultados.

Dos resultados, observa-se que o teste de hipótese realizado sobre o conjunto das dummies de interação (variáveis explicativas*ano99) não rejeita a suposição de que os coeficientes são os mesmos em ambos os períodos, para todas as quatro regressões estimadas. Precisamente, em todas as equações não se pode rejeitar a hipótese de igualdade dos coeficientes, nos dois períodos, a qualquer nível de significância abaixo de $5 \%$.

Através dos dados obtidos da regressão principal, mostrados na coluna (2.b), percebe-se que os resultados, qualitativamente, são basicamente os mesmos, apresentando sinais idênticos ao modelo anterior. Especificamente, sinal negativo para o coeficiente da variável "estmédio", que permanece estatisticamente significante. Também, correlação positiva para "conexões". Observase, também, mesmo sinal para a "diversidade" industrial e o custo de transporte, embora as variáveis não apresentem mais correlação estatística significante.

Ao contrário daqueles resultados exibidos na Tabela 7, os salários não estão mais correlacionados com o crescimento do emprego e seus coeficientes apresentam sinais negativos. Os resultados também revelam que a importância quantitativa de boa parte das variáveis explicativas do crescimento do emprego industrial se altera, tornando-se mais forte em períodos mais longos do que em fases intermediárias ou curtas.

\section{Conclusões}

Este trabalho teve dois objetivos principais. O primeiro deles foi caracterizar os níveis e o padrão espacial da concentração industrial, nas microrregiões brasileiras, para os anos de 1994 e 2004, buscando também identificar os clusters e outliers industriais e as áreas de maior dinamismo industrial. O segundo objetivo foi verificar quais eram os determinantes econômicos do crescimento do emprego da indústria estadual neste período.

A indústria é fortemente concentrada em microrregiões localizadas nas regiões Sul e Sudeste. Nas dez maiores participações no emprego, contudo, destaca-se a presença da microrregião de Fortaleza, sobretudo, no segmento de trabalho intensivo, onde sobe da $7^{\mathrm{a}}$ para a $4^{\mathrm{a}}$ posição nesta lista. No seg- 
Tabela 8: Determinantes do crescimento do emprego nos períodos 19941999 e $1999-2004$.

Regressão em pooling para a IT

Variável dependente - logarítmico do crescimento relativo do emprego

\begin{tabular}{|c|c|c|c|c|}
\hline Variáveis Explicativas & (1.a) & (1.b) & (2.a) & (2.b) \\
\hline ln_salmedio & $\begin{array}{r}-0.0050 \\
(0.0528)\end{array}$ & $\begin{array}{r}-0.0254 \\
(0.0585)\end{array}$ & $\begin{array}{r}-0.0283 \\
(0.0521)\end{array}$ & $\begin{array}{r}-0.0175 \\
(0.0571)\end{array}$ \\
\hline ln_estmedio & $-0.4138^{*}$ & $-0.4998^{*}$ & $-\frac{0.2662^{*}}{(0.0414)}$ & $\begin{array}{c}-0.3546^{*} \\
(0.0488)\end{array}$ \\
\hline ln_conexões & - & - & $\begin{array}{l}0.1931^{*} \\
(0.0332)\end{array}$ & $\begin{array}{l}0.2066^{*} \\
(0.0347)\end{array}$ \\
\hline ln_aglomdentro & - & - & $\begin{array}{r}-0.0303 \\
(0.0309)\end{array}$ & $\begin{array}{l}0.0039 \\
(0.0353)\end{array}$ \\
\hline ln_diversidade & - & - & $\begin{array}{r}-0.0279 \\
(0.0312)\end{array}$ & $\begin{array}{r}-0.1256 \\
(0.1010)\end{array}$ \\
\hline distmercado & $\begin{array}{l}0.3184^{*} \\
(0.0716)\end{array}$ & $\begin{array}{r}-1.0730 \\
(0.8742)\end{array}$ & $\begin{array}{l}0.3956^{*} \\
(0.0851)\end{array}$ & $\begin{array}{r}-0.9832 \\
(0.9098)\end{array}$ \\
\hline ln_salmedio*ano 99 & $\begin{array}{r}-0.0293 \\
(0.0748)\end{array}$ & $\begin{array}{r}-0.0316 \\
(0.0720)\end{array}$ & $\begin{array}{r}-0.0482 \\
(0.0738)\end{array}$ & $\begin{array}{r}-0.0331 \\
(0.0713)\end{array}$ \\
\hline ln_estmedio*ano 99 & $\begin{array}{l}0.0914 \\
(0.0474)\end{array}$ & $\begin{array}{l}0.0722 \\
(0.0456)\end{array}$ & $\begin{array}{l}0.0637 \\
(0.0593)\end{array}$ & $\begin{array}{l}0.0528 \\
(0.0574)\end{array}$ \\
\hline ln_conexões*ano99 & - & - & $\begin{array}{r}-0.0564 \\
(0.0445)\end{array}$ & $\begin{array}{r}-0.0445 \\
(0.0430)\end{array}$ \\
\hline ln_aglomdentro*ano99 & - & - & $\begin{array}{l}0.0034 \\
(0.0422)\end{array}$ & $-\frac{0.0033}{(0.0404)}$ \\
\hline ln_diversidade*ano 99 & - & - & $-\underset{(0.0319)}{0.0504}$ & $\begin{array}{r}-0.0487 \\
(0.0336)\end{array}$ \\
\hline distmercado*ano 99 & $\begin{array}{r}-0.0250 \\
(0.0377)\end{array}$ & $\begin{array}{r}-0.0427 \\
(0.0367)\end{array}$ & $\begin{array}{r}-0.1475 \\
(0.0837)\end{array}$ & $-\frac{0.1762}{(0.0910)}$ \\
\hline constante & $\begin{array}{c}-0.4173^{*} \\
(0.0732)\end{array}$ & $\begin{array}{l}1.0156 \\
(0.7786)\end{array}$ & $\begin{array}{c}-0.5430^{*} \\
(0.1225)\end{array}$ & $\begin{array}{l}0.3285 \\
(0.8984)\end{array}$ \\
\hline
\end{tabular}

Fonte: Estimação dos autores a partir dos dados da RAIS, IBGE e DNIT.

Nota: * $\mathrm{e}^{* *}$ indicam a significância estatística a $1 \%$ e $5 \%$, respectivamente. O desvio padrão é destacado entre parênteses e as regressões estão com correção para heteroscedasticidade (Matriz de White).

mento recursos naturais intensivos, que é o melhor distribuído espacialmente, as últimas quatro microrregiões pertencem ao Nordeste, em 1994. Já em 2004, o Nordeste aparece com duas e Centro-Oeste com uma microrregião.

O setor capital intensivo é o mais concentrado e de recursos naturais intensivos o menos concentrado. Enquanto a desconcentração industrial é mais forte para o segmento recursos naturais intensivos e mais fraca no de capital intensivo. No entanto, neste segmento, os resultados sugerem desconcentração para estados próximos a São Paulo. Nos outros dois segmentos analisados, relativamente, parece acontecer maior deslocamento das indústrias para outras regiões do país. Especialmente, para o Nordeste, no caso do trabalho intensivo.

Os clusters locais da participação do emprego, do tipo AA, são registrados no Sul e Sudeste do país, especialmente, nas microrregiões de São Paulo. Vale ressaltar que aparece, ainda, um destes na microrregião de Pacajus-CE. A análise LISA também detecta um bom número de associação espacial do tipo BA, 
sobretudo, no Nordeste e isso pode ser a indicação do surgimento de novos polos industriais nesta região, mas ainda sem efeitos na vizinhança. Os resultados da estatística espacial local, aplicado ao crescimento das participações microrregionais do emprego, também sugerem que as áreas de maior dinamismo em termos deste crescimento, com efeitos nas vizinhanças, situam-se em alguns estados pertencentes às regiões Nordeste e Centro-Oeste do país e no estado de Minas Gerais, o que caracteriza estas áreas como polos dinâmicos de crescimento. Estas evidências apontam, assim, para uma nova configuração industrial no Brasil.

Os resultados obtidos também apontam que os linkages de mercado são importantes para o crescimento do emprego industrial no Brasil no período 1994 a 2004 e nos subperíodos, o que defende o argumento da nova geografia econômica de que os efeitos de acesso ao mercado (linkages de demanda) e os linkages de custos favorecem a aglomeração e, assim, o crescimento local. As evidências também apontam que o crescimento do emprego industrial tende a ser maior em localidades com tamanho de firmas menores, sendo, portanto, consistente com os argumentos teóricos de Jacobs (1969) e Porter (1990), em que a competição local acelera o crescimento. Portanto, a importância dessas variáveis para o crescimento do emprego da indústria estadual parece não ser específica ao período ou à escolha dos anos polares estudados.

Para o período total, 1994-2004, foi verificado ainda que as economias de aglomeração também são benéficas para o crescimento do emprego industrial, mas apenas aquelas geradas das externalidades entre indústrias diferentes, favorecendo, assim, os argumentos teóricos de Jacobs (1969) e Fingleton (2003). Por fim, as medidas de custos de transporte e dos salários apresentam correlação negativa e positiva, respectivamente, com o crescimento do emprego industrial, quando são descontados os efeitos fixos, consistente também com os modelos da NGE, presentes, por exemplo, em Fujita et al. (2002).

\section{Referências Bibliográficas}

Kenneth Arrow. The economics implications of learning by doing. Review of Economics Studies, 29:155-173, 1962.

R. Bonelli. Ensaios sobre Politica Econômica e Industrialização no Brasil. SENAI, CIET, Rio de Janeiro, 1996.

Wilson Cano. Desequilíbrios Regionais e Concentração Industrial no Brasil: 1930-1995. Unicamp, Campinas, 1998.

André L. S. Chagas. Externalidades da aglomeração: Microfundamentação e evidências empíricas. Master's thesis, Universidade de São Paulo, São Paulo, 2004.

André L. S. Chagas e Rudnei Toneto Júnior. Fatores determinantes do crescimento local - evidências a partir de dados dos municípios brasileiros para o período 1980-1991. Pesquisa e Planejamento Econômico, 33(2):349-385, 2003.

M. Crozet. Do migrants follow market potentials? an estimation of a new economic geography model. Journal of Economic Geography, 4(4):439-458, 2004. 
Paulo Furquim de Azevedo e Rudnei Toneto Júnior. Relocalização do emprego industrial formal no brasil na década de 90. Pesquisa e Planejamento Econômico, 31(1):153-186, 2001.

Edson Paulo Domingues. Aglomerações e periferias industriais no brasil e no nordeste. Revista Econômica do Nordeste, 36(4):508-523, 2005.

Bernard Fingleton. Increasing returns: evidence from local wage rates in great britain. Oxford Economic Papers, 55:716-739, 2003.

M. Fujita e J. F. Thisse. Economics of Agglomeration: Cities, Industrial Location, and Regional Growth. Cambridge University Press, Cambridge, UK, 2002.

Masahisa Fujita, Paul Krugman, e Anthony J. Venables. Economia Espacial: Urbanização, prosperidade econômica e desenvolvimento humano mundo. Futura, São Paulo, 2002.

Rangel Galinari. Retornos crescentes urbano-industriais e spillovers espaciais: Evidências a partir da taxa salarial no estado de são paulo. Master's thesis, UFMJ, CEDEPLAR, Belo Horizonte, 2006.

E. L. Glaeser, H. D. Kallal, J. A. Sheinkman, e Andrei Sleifer. Growth in cities. Journal of Political Economy, 100(6):1126-1152, 1992.

Paulo Roberto Haddad, editor. Economia regional: teorias e métodos de análise. BNB. ETENE, Fortaleza, 1989.

Gordon H. Hanson. Regional adjustment to trade liberalization. Regional Science and Urban economics, 28(4):419-444, 1998.

Gordon H. Hanson. Market potencial, increasing returns and geographic concentrattion. Journal of International Economics, 67:1-24, 2005.

Vernon Henderson. Marshall's scale economies. Journal of Urban Economics, 53:1-28, 2003.

Rodolfo Hoffmann. Distribuição de Renda: medidas de desigualdades e pobreza. Edusp, São Paulo, 1998.

E. M. Hoover. The Location of Economic Activity. McGraw-Hill, New York, 1948.

Jane Jacobs. The Economy of Cities. Vintage, New York, 1969.

Paul Krugman. Increasing returns and economic geography. Journal of Political Economy, 99(3):483-499, 1991.

Robert E. Lucas. On the mechanics of economics development. Journal of Monetary Economics, 22(1):3-42, 1988.

Alfred Marshall. Principles of Economics. McMillan, 1920.

G. Mion. Spatial externalities and empirical analysis: the case of italy. Journal of Urban Economics, 56:97-118, 2004.

Mauricio M. Moreira e Sheila Najberg. Abertura comercial: criando ou exportando empregos? Pesquisa e Planejamento Econômico, 28(2):371-398, 1998. 
Cristiano Aguiar Oliveira. Crescimento econômico das cidades nordestinas: Um enfoque da nova geografia econômica. In IX ENCONTRO REGIONAL DE ECONOMIA. IX ENCONTRO REGIONAL DE ECONOMIA, 2004.

C. A. Pacheco. Novos padrões de localização no brasil? tendências recentes dos indicadores de produção e do investimento industrial. Texto para discussão IPEA, 1999.

M. E. Porter. The Competitive Advantage of Nations. Free Press, New York, 1990.

P. M. Romer. Increasing retunrns and long-run growth. Journal of Political Economy, 94(5):102-1037, 1986.

P. M. Romer. Endogenons technological change. Journal of Political Economy, 98(5):s71-s101, 1990.

Raul da Mota Silveira Neto. Concentração industrial regional, especialização geográfica e geografia econômica: Evidências para o brasil no período 19502000. Revista Econômica do Nordeste, 36(3):189-208, 2005.

A. J. Venables. Equilibrium locations of vertically linked industries. International Economic Review, 37(2):341-359, 1996. 